\title{
Using depolarization to quantify ice nucleating particle concentrations: a new method
}

\author{
Jake Zenker ${ }^{1}$, Kristen N. Collier ${ }^{1}$, Guanglang Xu ${ }^{1}$, Ping Yang ${ }^{1}$, Ezra J. T. Levin ${ }^{2}$, Kaitlyn J. Suski ${ }^{2, a}$, Paul J. DeMott ${ }^{2}$, \\ and Sarah D. Brooks ${ }^{1}$ \\ ${ }^{1}$ Department of Atmospheric Science, Texas A\&M University, College Station, TX 77843, USA \\ ${ }^{2}$ Department of Atmospheric Science, Colorado State University, Fort Collins, CO 80526, USA \\ anow at: Pacific Northwest National Laboratory, Richland, WA 99352, USA
}

Correspondence to: Sarah D. Brooks (sbrooks@tamu.edu)

Received: 23 May 2017 - Discussion started: 12 July 2017

Revised: 5 October 2017 - Accepted: 8 October 2017 - Published: 1 December 2017

\begin{abstract}
We have developed a new method to determine ice nucleating particle (INP) concentrations observed by the Texas A\&M University continuous flow diffusion chamber (CFDC) under a wide range of operating conditions. In this study, we evaluate differences in particle optical properties detected by the Cloud and Aerosol Spectrometer with POLarization (CASPOL) to differentiate between ice crystals, droplets, and aerosols. The depolarization signal from the CASPOL instrument is used to determine the occurrence of water droplet breakthrough (WDBT) conditions in the CFDC. The standard procedure for determining INP concentration is to count all particles that have grown beyond a nominal size cutoff as ice crystals. During WDBT this procedure overestimates INP concentration, because large droplets are miscounted as ice crystals. Here we design a new analysis method based on depolarization ratio that can extend the range of operating conditions of the CFDC. The method agrees reasonably well with the traditional method under non-WDBT conditions with a mean percent error of $\pm 32.1 \%$. Additionally, a comparison with the Colorado State University CFDC shows that the new analysis method can be used reliably during WDBT conditions.
\end{abstract}

\section{Introduction}

Ice clouds cover approximately $40 \%$ of the Earth's atmosphere (Wylie and Menzel, 1999). Because of their complicated microphysical properties, ice and mixed-phase clouds pose challenges in understanding our global radiative budget and precipitation (Wendisch et al., 2005; Pinto, 1998; Yang et al., 2015; Korolev, 2007). Despite several decades of effort by the atmospheric community to study ice clouds, there are still large gaps in our understanding of the impacts they have on our climate (Boucher et al., 2013). While experimental chambers have been used to study ice nucleation processes and ice nucleating particle (INP) concentrations for more than 30 years, INP measurement techniques are still under development.

Ice nucleation measurements are challenging for several reasons. The concentration of effective INPs is typically 0.1 to $1000 \mathrm{~L}^{-1}$ or $\sim 10^{-6}$ to $10^{-4}$ of the total aerosol concentration (DeMott et al., 2003, 2015; Jiang et al., 2014; Mason et al., 2016; Cziczo et al., 2017). Secondly, differentiating between ice crystals and droplets using particle discrimination methods is experimentally challenging. Thirdly, ice crystals can nucleate via several mechanisms (Vali, 1985; Vali et al., 2015), and accurate measurements must account for ice crystals initiated by each of these mechanisms.

At temperatures below $\sim-36^{\circ} \mathrm{C}$, ice crystals can nucleate homogeneously from water droplets. At higher temperatures, an aerosol particle is needed to act as an INP which facilitates the formation of an ice crystal via heterogeneous nucleation. Heterogeneous nucleation pathways include depositional nucleation, which occur through the direct deposition of water vapor on an INP surface. Immersion freezing occurs when an INP embedded within a water droplet enters a cooler environment and nucleates an ice crystal. Evidence suggests that immersion freezing provides the largest contribution to ice crystal nucleation in clouds (De Boer et 
al., 2011; Murray et al., 2012). In addition, when an aerosol forms a solution droplet below the melting point, condensational freezing may occur. Finally, contact freezing occurs when an aerosol in contact with a water droplet surface initiates freezing. While the exact mechanism of contact freezing remains unresolved, it has been shown that the presence of an INP positioned at a droplet surface facilitates freezing at temperatures several degrees warmer than immersion freezing with identical INPs (Fornea et al., 2009; Brooks et al., 2014; Durant and Shaw, 2005). Knowledge of each of these mechanisms is important for understanding the formation of ice in mixed-phase clouds (containing droplets and ice crystals) and for developing robust parameterizations for global climate models (Tan et al., 2016; Pithan et al., 2014).

Composition, surface structure, and size are important factors in determining the ice nucleating ability of an aerosol particle (Zolles et al., 2015; Niemand et al., 2012; Hoose and Möhler, 2012). Measurements suggest that K-feldspar, a common component of soil dust aerosol, may account for a large fraction of Earth's INPs (Atkinson et al., 2013; YakobiHancock et al., 2013). Recent investigations of other aerosols have identified aromatic pollutant aerosols, secondary organic aerosols, marine aerosols, and aerosols produced from biomass burning as effective INPs (Brooks et al., 2014; DeMott et al., 2016; McCluskey et al., 2014, 2016; Levin et al., 2016; Collier and Brooks, 2016).

Optical techniques have been used to detect and characterize ambient ice crystals (Mishchenko and Sassen, 1998; Yoshida et al., 2010; Noel and Sassen, 2005). For example, lidar observations use the depolarization ratio to distinguish cloud particle type (i.e., ice crystals or water droplets). In traditional lidar applications, the depolarization ratio is calculated using Eq. (1):

$\delta_{\text {Lidar }}=\frac{B_{\perp}}{B_{\|}}$,

where $B_{\perp}$ and $B_{\|}$are the perpendicular and parallel components of the lidar signal retrieved from the ambient atmosphere or clouds. Under single scattering conditions, the depolarization ratio associated with an ensemble of water droplets is essentially zero while the counterpart for ice crystals is nonzero with a specific value depending on particle habit and orientation. Ice crystal depolarization ability is attributed to the high irregularities in the shapes and surfaces of ice crystals (Bohren and Huffman, 1983). The number of INPs present in a cloud can dictate its optical properties throughout the ice nucleation process (Hoose and Möhler, 2012; Murray et al., 2012).

Several previous studies have designed new analysis methods for ice chambers that utilize the depolarization ratio measured by optical particle counters (OPCs) (Glen and Brooks, 2014; Nicolet et al., 2010; Clauss et al., 2013; Garimella et al., 2016). Nicolet et al. (2010) accurately quantified ice crystals in the presence of water droplets in a chamber by using the peak intensity of the depolarization ratio to discriminate between ice crystals and droplets with the Ice Optical DEtector (IODE). Rather than using the peak intensity of the depolarization signal, Clauss et al. (2013) used the width of the pulse detected in the depolarization channel of the Thermo-stabilized Optical Particle Spectrometer for the detection of Ice (TOPS-ice) for phase discrimination. Alternatively, Garimella et al. (2016) used a machine learning technique with scattering signals, including linear depolarization signals detected by an OPC installed in the SPectrometer for Ice Nuclei (SPIN, Droplet Measurement Technologies, Inc.) to determine INP concentration.

A continuous flow diffusion chamber (CFDC) designed to measure ice nucleation was originally developed by Rogers (1988) at the University of Wyoming and was later modified and rebuilt at Colorado State University (CSU). Several other ice nucleation chambers have been developed since then including the CFDC at Texas A\&M University (TAMU) used in this study. Many enhancements have been made to ice nucleation chambers (e.g., Rogers et al., 2001; Creamean et al., 2013; DeMott et al., 2015; Prenni et al., 2013; Coluzza et al., 2017; Kanji et al., 2017), including replacement of the TAMU CFDC's standard optical detector (CLIMET, model no. CI-3100), which uses particle size to distinguish ice crystals from water droplets and aerosols, with the Cloud and Aerosol Spectrometer with POLarization (CASPOL, Droplet Measurement Technologies, Inc.). The CASPOL detects forward scattering, backward scattering, and depolarization on a single particle basis. In addition, the CASPOL has been used to differentiate between ice crystals and various types of dust and soil particles based on backward scattering and depolarization signals (Glen and Brooks, 2013, 2014).

In this study, we demonstrate how differences in particle optical properties can be used to differentiate between ice crystals, droplets, and aerosols detected by the CASPOL. In addition, we present a new method to quantify INP concentrations detected by the TAMU CFDC using depolarization ratio. Finally, INP concentrations obtained using the new method are compared with results obtained through the traditional analysis method that primarily uses particle size to identify INP as well as INP concentrations reported by another ice nucleation chamber, the CSU CFDC.

\section{Experimental}

\subsection{The TAMU CFDC and CASPOL}

The TAMU CFDC was custom built in our laboratory at Texas A\&M University and has been operated in previous laboratory and field campaigns to take temperature- and supersaturation-resolved INP concentration measurements (Glen and Brooks, 2014; McFarquhar et al., 2011). Additional details on CFDC and CFDC-CASPOL instrument design and operation are provided in our previous work (Glen 
and Brooks, 2013, 2014; Glen, 2014). Hereafter, CFDC refers to the TAMU CFDC unless otherwise stated.

During operation, sample aerosols pass through a diffusion dryer to remove moisture from the air and before they enter the CFDC. Typically, aerosol flow is directed through a BGI Sharp Cut Cyclone impactor (model 0.732) prior to entering the CFDC in order to remove aerosols with a diameter greater than $\sim 1.75 \mu \mathrm{m}$ from the sample flow. However, the data presented here were collected by the TAMU CFDC-CASPOL during the second phase of the Fifth International Ice $\mathrm{Nu}$ cleation Workshop campaign (FIN-02) and no impactor was used during the campaign. Reasons for this choice were that the objective of FIN-02 was intercomparison with other instruments that did not have impactors available, aerosol size distributions were well characterized, and supermicron particle numbers were small.

Next, aerosols enter the CFDC processing chamber where temperature and supersaturation are controlled. The processing chamber consists of two concentric cylindrical walls coated with ice. Separate refrigeration units on each wall can be controlled to create a temperature gradient in the chamber that imposes a region of supersaturation with respect to ice $\left(\mathrm{SS}_{\mathrm{i}}\right)$ in the CFDC. The CFDC chamber is $75 \mathrm{~cm}$ long. The bottom $25 \mathrm{~cm}$ of the walls is coated with hydrophobic Teflon to prevent water from freezing to the wall in this region. This section of the chamber is referred to as the evaporation region because it remains subsaturated with respect to water and partially or completely evaporates any water droplets that nucleate in the CFDC. The separate wall temperatures are manually controlled and monitored through a LabVIEW program. The temperature and supersaturation conditions at the position of the sheath air surrounded aerosol lamina are calculated using analytical equations reported in Rogers (1988).

Before measurements can be taken with the CFDC, the processing chamber must be prepared. First, a vacuum pump is used to evacuate the chamber for approximately $30 \mathrm{~min}$ in order to eliminate ambient aerosols that may have infiltrated the chamber and to remove moisture that may cause the walls to accumulate an uneven coating of ice or allow ice to accumulate in other sensitive regions. The walls are then cooled to a temperature of $-25^{\circ} \mathrm{C}$ and the CFDC walls are iced by pumping Nanopure water into the chamber from the base. Excess water is drained out of the instrument for approximately a minute after icing is complete. Then, the chamber is evacuated and refilled with $\mathrm{N}_{2}$ gas once more before sampling is initiated.

At the base of the processing chamber, particles pass through a detector to determine INP concentration. In previous TAMU CFDC studies, either an OPC (Climet, Inc.) or the CASPOL were employed (Glen and Brooks, 2014; McFarquhar et al., 2011). During FIN-02, the CASPOL was the chosen detector. Two mass flow controllers downstream of the CASPOL are used to set the total flow and recirculating sheath flow through the CFDC-CASPOL. The difference between the total and sheath flows determines the sam- ple flow. For this campaign, the total flow was set to values ranging from 6 to $9 \mathrm{~L} \mathrm{~min}^{-1}$ and the sheath flow was set to values ranging from 4 to $7 \mathrm{~L} \mathrm{~min}^{-1}$, resulting in a sample flow that was typically $\sim 2 \pm 0.5 \mathrm{~L} \mathrm{~min}^{-1}$. During operation, the CFDC made scans from low to high supersaturation at a constant aerosol lamina temperature $\left( \pm 1.5^{\circ} \mathrm{C}\right)$. This is accomplished by increasing wall temperature difference in a manner that retains the desired temperature at the position of the aerosol lamina.

The CASPOL (Droplet Measurement Technologies, Inc.) is a prototype particle-by-particle counter. Laser light $(680 \mathrm{~nm})$ is scattered by single particles entering the CASPOL and detected by three detectors that give information about the optical properties: a forward scatter detector, a backward scatter detector with a parallel polarized filter, and a backward scatter detector with a perpendicular polarized filter. Particles are sized according to the intensity of light, which reaches the CASPOL's forward scatter detector, as in a traditional OPC. The forward scattering detector of the CASPOL registers particles on an individual basis and sorts those particles into a series of size bins ranging from 0.6 to $50 \mu \mathrm{m}$ optical diameter. In addition, the instrument has a fourth detector that determines whether a particle is properly aligned in the laser beam and should thus be recorded.

The depolarization ratio derived from CASPOL measurements is defined as follows (Glen and Brooks, 2014):

$\delta_{\mathrm{CAS}}=\frac{B_{\perp, \mathrm{CAS}}}{B_{\perp, \mathrm{CAS}}+B_{\|, \mathrm{CAS}}}$,

where $B_{\perp, \mathrm{CAS}}$ and $B_{\|, \mathrm{CAS}}$ denote the signals from the CASPOL's perpendicular and parallel backward scattering detector, respectively. This definition differs somewhat from the conventional depolarization ratio used in remote sensing based on lidar observations. The main difference is that the CASPOL detects light at the back scattering angles of 168 to $176^{\circ}$ rather than precisely $180^{\circ}$ in the case of lidar. Also, the CASPOL occasionally detects a particle for which the parallel backscatter signal is below the limit of detection and thus is registered as zero, while the same particle has a nonzero perpendicular signal. In such cases, the calculated lidar depolarization ratio of such particles is of spurious singularity. In contrast, the value of depolarization ratio calculated by Eq. (2) in the aforementioned case yields a value of unity, making the depolarization ratio of these particles quantitatively meaningful. Likewise, in cases where the perpendicular backscatter is below the limit of detection, the reported depolarization ratio is also unity.

\subsection{Data collection during FIN-02}

The second phase of FIN-02 took place at the Institute of Meteorology and Climate Research: Atmospheric Aerosol Research (IMK-AAF) facility at the Karlsruhe Institute of Technology (KIT) in Karlsruhe, Germany (DeMott et al., 2017). Two specialized chambers at KIT were used in this 
campaign: the Aerosols Interaction and Dynamics in the Atmosphere (AIDA) chamber and the Aerosol Preparation and Characterization (APC) chamber. The AIDA chamber can be used to simulate atmospheric conditions that give rise to cloud particle formation and growth and has been used in many previous campaigns and instrument intercomparisons to examine the ice nucleating ability of various aerosols (Amato et al., 2015; Schnaiter et al., 2016; Wagner et al., 2015; DeMott et al., 2011). The AIDA chamber is a threestory, $84 \mathrm{~m}^{3}$ volume chamber that uses adiabatic expansion to simulate the atmospheric conditions required for ice nucleation to occur. During FIN-02, aerosols were drawn from the AIDA chamber by the various ice nucleation instruments prior to expansion. Following the aerosol sampling period, an AIDA expansion was performed so that INP concentration determined by AIDA could be compared to results from the various visiting instruments. The second chamber, the $\mathrm{APC}$, is a $3.7 \mathrm{~m}^{3}$ volume chamber in which aerosols of a selected composition are produced by atomization and solid aerosol generation methods, suspended in dry synthetic air, uniformly distributed with a mixing fan, and maintained at constant temperature and pressure (Linke et al., 2006). While the APC lacks the adiabatic expansion capabilities of AIDA, the APC was used during FIN02 to provide a uniformly high concentration of aerosols of various compositions. Samples were subsequently distributed to the participating ice nucleation instruments.

During the campaign groups from 22 institutions sampled both the AIDA and APC chambers using a variety of online and offline ice nucleation measurement techniques. For verification of the TAMU CFDC-CASPOL measurements and new analysis method, we compare our results to the measurements of the CSU CFDC. In order to test the CASPOL detector response to ice and non-ice particles, auxiliary measurements of olive oil droplets, ambient aerosols, and homogeneously frozen ice crystals are also evaluated and compared to the TAMU CFDC-CASPOL heterogeneous nucleation data collected during FIN-02.

\subsection{CFDC-CASPOL data analysis}

CFDC-CASPOL data are sorted into 1 min segments in order to achieve a sufficient sample volume detected by the CASPOL. Temperature, pressure, sample, and sheath flows are used to determine a standard temperature and pressure $(273 \mathrm{~K}, 1013.5 \mathrm{mb})$ sample volume, which is used to convert the raw count of particles in each $1 \mathrm{~min}$ segment to a concentration. Occasionally ice particles may detach from the icecoated walls. To account for this, a filter is placed upstream of the sample inlet in order to determine background signal of the CFDC chamber. The background period that is closest to a given $1 \mathrm{~min}$ sample period is applied by subtracting that background concentration from the total concentration measured by the CASPOL at the sample time.
The traditional analysis method counts INPs based on a nominal size cut of $2 \mu \mathrm{m}$ in diameter in order to discriminate between unactivated aerosols and ice crystals. The approximate size cuts has been determined by modeling calculations indicate that ice nucleating in the CFDC will grow beyond this size diameter (Rogers, 1988). During FIN-02, data collected by the CASPOL's forward scattering detector were used for the traditional analysis. The CASPOL forward scattering signal is accurately calibrated for spherical particles. For nonspherical ice crystals, the particle size-scattering relationship is less certain.

\subsection{Limitations of the traditional analysis method}

There are several limitations to the traditional analysis method used to process CFDC data, which relies on size alone to differentiate ice from water particles (as described in Sect. 2.3). As previously mentioned, supercooled water droplets may form in the chamber in conditions supersaturated with respect to water $\left(\mathrm{SS}_{\mathrm{w}}\right)$. At high $\mathrm{SS}_{\mathrm{w}}$, water droplets may pass through the evaporation region without fully evaporating. Any droplets that remain larger than the nominal size cut and reach the detector will be miscounted as ice crystals. This phenomenon is referred to as water droplet breakthrough (WDBT).

WDBT is a common issue in continuous flow ice nucleation instruments, although the point at which WDBT occurs varies between instruments of differing dimensions and even as a function of operating conditions (especially temperature) within a single instrument (Rogers et al., 2001; DeMott et al., 2015; Garimella et al., 2016). CFDCs in use today are custom-built instruments which vary in physical dimensions and choice of detector, although all operate under the same basic principles. Due to the combination of different chamber dimensions, flow rates, operating conditions (temperature and supersaturation) in the growth and evaporation regions within the instrument, and the choice of detector and size cutoff, WDBT varies from instrument to instrument. In some cases, it can be difficult to determine when WDBT is occurring; if the instrument is unintentionally operated at supersaturations above WDBT, droplets will be miscounted as ice crystals. Even within a single instrument, specific conditions of WDBT vary with operating temperature, the ambient humidity, the hygroscopicity and the size of sample aerosols, and the sample flow, which determines the residence time in the instrument. Typically, in the TAMU CFDC the onset of WDBT occurs at 3 to $4 \% \mathrm{SS}_{\mathrm{w}}$ but has been observed as low as $1 \% \mathrm{SS}_{\mathrm{w}}$ and as high as $8 \% \mathrm{SS}_{\mathrm{w}}$. A new analysis method would be valuable for overcoming the challenges presented by WDBT.

In the traditional analysis, any aerosols larger than the nominal size cut are miscounted as INPs. Operation with an upstream impactor reduces this problem. However, depending on the flow, 1 to $10 \%$ of particles larger than $2 \mu \mathrm{m}$ may make it into the chamber to contribute to the apparent INP 
signal. A new analysis method that differentiates between large aerosols and ice crystals is needed since it would remove the need to limit the size of particles allowed into the instrument in the first place.

\subsection{Auxiliary CASPOL measurements}

Measurements were taken with the CASPOL independent of the CFDC to provide instrument response to various types of particles, which may coincidently reach the detector during CFDC-CASPOL operation.

One population of interest is water droplets. The Vibrating Orifice Aerosol Generator (VOAG) (TSI, Inc., model 3450) was used with olive oil solutions to produce monodisperse spherical droplets of chosen sizes as a proxy for water droplets that form in the CFDC. Though the index of refraction of olive oil (1.44 to 1.47) is slightly higher than water (1.33) (Hecht and Zajac, 2002), these droplets are a reasonable approximation for the depolarization ratio signal of water droplets because they are uniform spheres. As reported in Glen and Brooks (2013), the uncertainty in sizing due to differences in the complex refractive indices of oil and water are up to $30 \%$ based on a comparison of VOAG oil droplet calibrations of CASPOL to water-based calibrations performed by the manufacturer. For this project, droplets were generated with the diameters of $2 \pm 0.6,6 \pm 1.8,8 \pm 2.4$, and $10 \pm 1.5 \mu \mathrm{m}$.

For VOAG droplet generation, a separate olive oil and 2-propanol solution is prepared for each desired size. The VOAG's vibration frequency and dispersion and dilution flows are set according to computed specifications as detailed in the VOAG manual and as previously performed (Glen and Brooks, 2013, 2014). Downstream of the VOAG, the sample droplets travels through a charge neutralizer (Aerosol Neutralizer 3054A, TSI Inc.) to prevent particle loss since charged particles tend to be attracted to the walls of sample tubing. Following the neutralizer, sample flow is split between flow to the CASPOL, controlled by a mass flow controller and a Gast air pump on the downstream side, and a dump line which allows for excess flow generated from the VOAG to be expelled from the system. For each size, data are collected for roughly 15 min during which approximately 10000 droplets are sampled. It was observed that a mode of small (submicron diameter) residual 2-propanol do not evaporate but remain in the sample flow and are detected by the CASPOL. For this reason, all particles less than $1 \mu \mathrm{m}$ are removed from the dataset during processing.

The CASPOL's response to a second population of interest, ambient aerosol, was also evaluated for the new analysis method. Aerosol was sampled at the Storm Peak Laboratory (SPL) in Steamboat Springs, CO during the third phase of FIN-03 in September 2015. The use of a diverse aerosol population is necessary to ensure that the new analysis method be successful at discriminating ice crystals in the CFDC from a wide range of aerosols. SPL is an ideal sampling location because the aerosol population comes from many sources including mineral dust, organics from deciduous and coniferous forests, biomass burning aerosols that have been transported from forest fires in the western United States, and sulfates that are produced by two coal burning power plants that are located approximately 50 and $100 \mathrm{~km}$ from the laboratory. Ambient aerosol sampling at SPL was accomplished by connecting the CASPOL directly to an ambient sample inlet in the laboratory for a total time of $92 \mathrm{~h}$ over a 7 -day period.

Thirdly, a population of ice crystals was needed for the new method. CFDC-CASPOL measurements were taken under conditions that approached those needed for homogeneous freezing, thus generating higher concentrations of ice crystals in the absence of activated liquid droplets. These measurements are detailed in Glen and Brooks (2014). For these measurements, the sample flow was conditioned with a pre-cooler, which was set to $-10^{\circ} \mathrm{C}$ to remove excess moisture and the CFDC was operated at $-55 \pm 0.2{ }^{\circ} \mathrm{C}$ and $51 \pm 2.3 \% \mathrm{SS}_{\mathrm{i}}\left(-11 \pm 1.5 \% \mathrm{SS}_{\mathrm{w}}\right)$. Under these conditions, we can ensure that all particles larger than the $2 \mu \mathrm{m}$ size cut were frozen, which is the goal of this experiment.

For clarity, the CASPOL measurements of the VOAG droplets, ambient aerosols collected at SPL, and ice crystals generated in homogeneous conditions are referred to as droplet, aerosol, and ice crystal training datasets, respectively.

\section{Results}

\subsection{Discriminating water droplets, aerosols, and ice crystals with optical signatures}

This analysis used optical differences between ice crystals, droplets, and aerosols in order to identify and quantify ice crystals that form in the CFDC. The CASPOL has been used previously to discriminate between different aerosol populations using an empirical tool known as an optical signature (Glen and Brooks, 2013). In an analogous method, optical signatures produced from CALIPSO satellite backscatter and depolarization data have been used to identify cloud phase (Hu et al., 2009).

In Fig. 1a-c, CASPOL optical signatures for ice, droplet and aerosol training data are shown, respectively. The signatures show depolarization ratio (as defined in Eq. 2) versus total backscatter. The signatures are generated by defining a $50 \times 50$ Cartesian grid with depolarization ratio on the $x$ axis and total backscatter (calculated as the sum of the CASPOL's parallel and perpendicular signal intensities) on the $y$ axis. Each particle detected by the CASPOL is placed in the appropriate grid cell. The color scale in Fig. 1. reports the fraction of particles in a dataset that populate that grid cell. Each training dataset contains some particles that are highly backscattering and some particles that are highly depolarizing, but only the ice crystal population contains particles that 

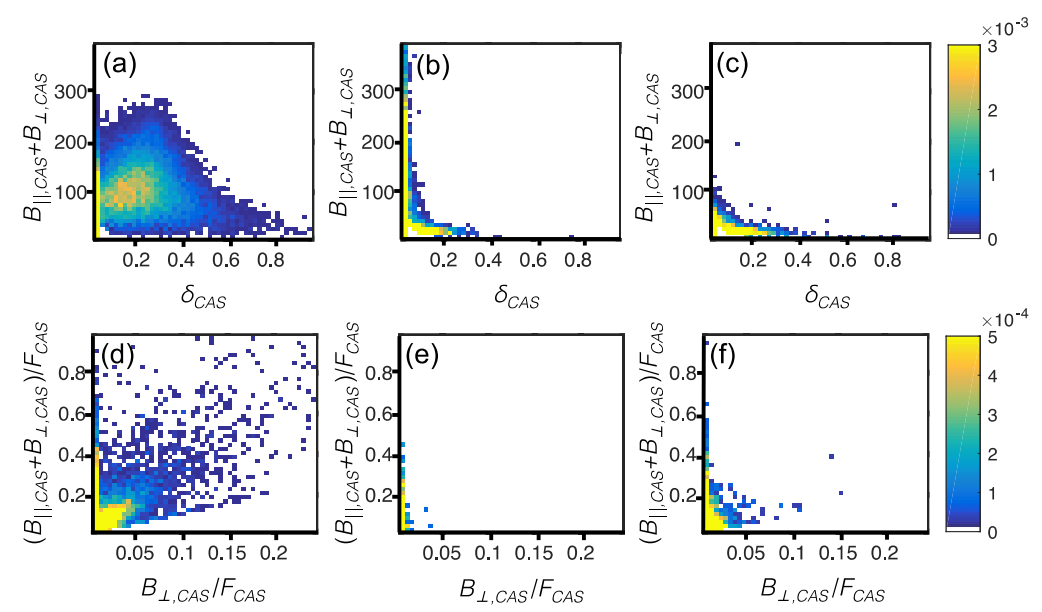

Figure 1. Optical signatures of training data populations: ice crystals $(\mathbf{a}, \mathbf{d})$, droplets $(\mathbf{b}, \mathbf{e})$, and aerosol (c, f). The CASPOL signals used to generate these signatures are parallel back scatter $\left(B_{\| \mathrm{CAS}}\right)$, perpendicular back scatter $\left(B_{\perp, \mathrm{CAS}}\right)$, and forward scatter $\left(F_{\mathrm{CAS}}\right)$. The shading scales indicate the fraction of the training dataset that populates a grid cell.

have both a high depolarization ratio and high backscatter signal.

In Fig. 1d-f, optical signatures normalized with respect to forward scatter, $F$, are displayed. Here the total backscatter ratio of signal to forward scatter signal is plotted against the back-perpendicular ratio of signal to forward signal. The back-perpendicular-to-forward ratio is a measure of depolarizing ability normalized by size (which is determined by the forward signal, $F$ ). In Fig. 1d-f, we see that very few aerosols and droplets achieve a back perpendicular to forward ratio larger than 0.05 . In contrast, many of the ice crystal training dataset particles exceed that value.

Consistent with the findings of Glen and Brooks (2013), CASPOL optical signatures can be used as an empirical tool to detect differences in the bulk optical properties of different particle populations. However, in order to design a new analysis method, it is necessary to gain a quantitative understanding of how the CASPOL detects single particles as opposed to bulk populations of particles.

\subsection{Modeling the depolarization ratio of water droplets, aerosols, and ice crystals}

Model calculations can provide insight on how particles depolarize light in the CASPOL. To perform model calculations, we first must define the relation between the CASPOL depolarization ratio (Eq. 2) and the scattering phase matrix. The CASPOL laser emits an incident beam that propagates along the $z$ direction in the form

$\boldsymbol{E}_{i}=\left(\begin{array}{c}E_{\| i} \\ E_{\perp i}\end{array}\right) e^{i(k z-\omega t)}=\left(\begin{array}{c}E_{\| i} \\ 0\end{array}\right) e^{i(k z-\omega t)}$,

where $\boldsymbol{E}_{i}$ is the incident electric field, $E_{\| i}$ and $E_{\perp i}(=0)$ are the parallel and perpendicular components with respect to the scattering plane, $k$ is wave number, $\omega$ is frequency, and $t$ is time. The scattering plane is defined as a plane through the $z$ axis and the line linking the particle and detection point. The scattered light at a sufficiently large distance (i.e., in the far-field zone) is related to the incident light in the form

$$
\begin{aligned}
\boldsymbol{E}_{\mathrm{S}} & =\frac{e^{i k(r-z)}}{-i k r}\left(\begin{array}{ll}
S_{2} & S_{3} \\
S_{4} & S_{1}
\end{array}\right)\left(\begin{array}{l}
E_{\| i} \\
0
\end{array}\right) \\
& =\frac{e^{i k(r-z)}}{-i k r}\left(\begin{array}{l}
S_{2} \\
S_{4}
\end{array}\right) E_{\| i},
\end{aligned}
$$

where $r$ is the distance between the particle and detector and $S_{i}(i=1,2,3,4)$ are elements of the amplitude matrix. The model depolarization ratio, $\delta_{\text {Model }}$, can be expressed as follows:

$$
\begin{aligned}
\delta_{\text {Model }}(\theta) & =\frac{B_{\perp, \text { Model }}(\theta)}{B_{\perp, \text { Model }}(\theta)+B_{\|, \text {Model }}(\theta)} \\
& =\frac{\left|S_{4}(\theta)\right|^{2}}{\left|S_{4}(\theta)\right|^{2}+\left|S_{2}(\theta)\right|^{2}},
\end{aligned}
$$

where $\theta$ is the detection angle, and $B_{\|, \text {Model }}$ and $B_{\perp, \text { Model }}$ are the modeled parallel and perpendicular backscattered intensities. Using the following relations between the elements of scattering phase matrix, $P_{i j}(i, j=1,2,3,4)$, and the elements of amplitude matrix, $S_{i}(i=1,2,3,4)$,

$$
\begin{aligned}
& \left|S_{4}(\theta)\right|^{2}+\left|S_{2}(\theta)\right|^{2} \sim\left(P_{11}(\theta)+P_{12}(\theta)\right) \times C_{\text {sca }}, \\
& \left|S_{4}(\theta)\right|^{2}-\left|S_{2}(\theta)\right|^{2} \sim\left(P_{21}(\theta)+P_{22}(\theta)\right) \times C_{\text {sca }},
\end{aligned}
$$

where $C_{\mathrm{sca}}$ is the scattering cross section of a particle. As described above, the CASPOL detects light over a narrow range of back scattering angles, 168 to $176^{\circ}$. To compare to the CASPOL measurements, we define the mean modeled depolarization ratio over the angular range of 168 to $176^{\circ}$ and is expressed below in Eq. (8). 


$$
\begin{aligned}
& \bar{\delta}_{\text {Model }}\left(168^{\circ}: 176^{\circ}\right)= \\
& \frac{\int_{168^{\circ}}^{176^{\circ}}\left(P_{11}(\theta)+P_{12}(\theta)-P_{21}(\theta)-P_{22}(\theta)\right) \sin (\theta) \mathrm{d} \theta}{2 \int_{168^{\circ}}^{176^{\circ}}\left(P_{11}(\theta)+P_{12}(\theta)\right) \sin (\theta) \mathrm{d} \theta}
\end{aligned}
$$

To compute the scattering phase matrices of these models with specific sizes at CASPOL wavelength, we apply socalled improved geometric optics method (IGOM) for particle with relatively large size and the invariant imbedding T-matrix method (II-TM) for particles with relatively small sizes (Yang and Liou, 1996; Bi et al., 2013; Bi and Yang, 2014; Johnson, 1988). The combination of these two methods is chosen because of the different size parameters of the aerosol and ice crystal populations. The T-matrix method is a highly accurate method for calculating scattering properties of atmospheric particles (Koepke et al., 2015; Brooks et al., 2004). However, it becomes impractical for large particles due to its excessive demands on the computational power. In contrast, the IGOM is accurate over the range of particle sizes over which the particle size to be much larger than the incident wavelength (Xu et al, 2017).

Three idealized ice crystal habits were modeled: a hexagonal column, a hexagonal plate, and a droxtal. These shapes represent generalizations of common ice crystal habits (Bailey and Hallett, 2009). An idealized dust-like particle with fractal facets was used to model aerosols (Liu et al., 2013). These particles are nonspherical and thus will yield different measured depolarization ratios depending on their orientation in the CASPOL. The model provides the mean depolarization ratio over all orientations with respect to the laser beam. In contrast, the theoretical depolarization of water droplets is zero at all sizes.

Figure 2 shows the depolarization ratios as a function of size for the three ice crystal habits, dust-like aerosol, and water droplets. For hexagonal columns, hexagonal plates, and droxtals, the depolarization ratio increases from less than 0.05 to as high as 0.35 as the optical diameter increases from 0.5 to $8 \mu \mathrm{m}$ diameter. Above $8 \mu \mathrm{m}$, the depolarization ratio for droxtals and columns continue to rise, while the values for plates decrease to $\sim 0.25$. The droxtal depolarization ratios are quite low. Thus, while columns and plates could be distinguished from water droplets based on depolarization ratio alone, droxtals could not be distinctly identified. It is not known which of these habits best represents individual ice crystals nucleated and grown in the CFDC. Fortunately, if it is assumed that only particles of $2 \mu \mathrm{m}$ diameter or larger are ice crystals in the CFDC, these theoretical results show that discrimination between water droplets and any of the three habits of ice crystals is possible. Thus, consideration of depolarization ratio should provide a large improvement in particle discrimination.

Similar to ice crystals, depolarization ratios of the modeled dust aerosols increase with particle diameter. At most sizes, the aerosol data fall within the range of depolariza-

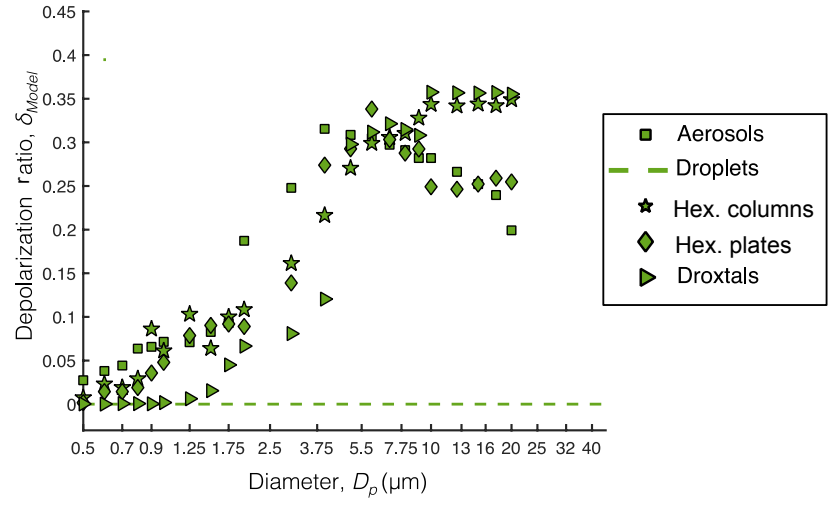

Figure 2. Depolarization ratio vs. diameter for modeled particles: droplets, aerosols, hexagonal column ice crystals, hexagonal plate ice crystals, and droxtals.

tions ratios reported for the three ice crystal shapes. This indicates that the use of depolarization ratios will not make an improvement in differentiating between aerosols and ice crystals. Fortunately, the traditional CFDC method incorporates the use of an impactor to physically remove aerosols greater than $1.75 \mu \mathrm{m}$ from the sample flow prior to entering the chamber, coupled with the analysis strategy, which only counts particles that are larger than the nominal size cutoff (at least $2 \mu \mathrm{m}$ diameter) as ice crystals. Thus, the traditional method is already sufficient for differentiating between aerosols and ice crystals.

\subsection{Determination of optical properties of aerosols, droplets, and ice crystals}

In this section, we empirically test the assertion that the CASPOL depolarization ratio can be used to discriminate ice crystals from aerosols and water droplets. To accomplish this, the training datasets of droplets, aerosols, and ice crystals shown above (Fig. 1) are examined further. The lognormal size distributions (shown as a percent of population) observed by the CASPOL for the droplet, aerosol, and ice crystal training data are shown in Fig. 3a. Each VOAG size in the droplet training dataset is treated as a separate population and plotted as a separate line in the figure. As seen in Fig. 1a, the size distributions of droplets, aerosols, and ice crystals overlap. This demonstrates the primary disadvantage to using particle diameter as the sole criteria to identify ice crystals.

For each training dataset, the frequency distribution of depolarization ratio reported as a percentage of the total particles in the dataset is shown in Fig. 3b. As seen in the figure, droplets have depolarization ratios up to 0.3. Therefore, we visually assign 0.3 as the nominal depolarization threshold cutoff for differentiating between ice crystals and non-ice particles. The choice on 0.3 is further evaluated in Sect. 3.7. Unfortunately, a small percentage of aerosols do 

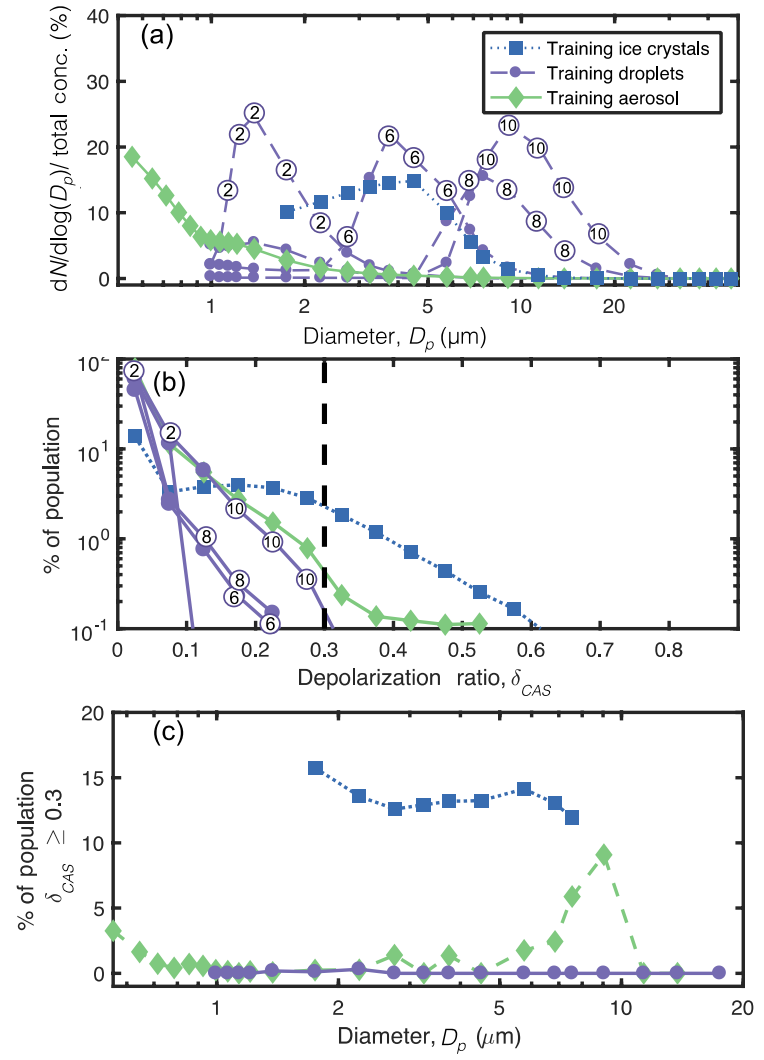

Figure 3. (a) Percent lognormal size distribution, (b) frequency distribution of depolarization ratios, and (c) the percentage of the particles with depolarization ratios above the threshold of 0.3 are shown for training data droplets, aerosols, and ice crystals as detected by the CASPOL. In panel (b), the depolarization ratio threshold value of 0.3 is indicated by the dashed line. In panel $(\mathbf{a}, \mathbf{b})$, the numbers displayed in circles provide the diameter in micrometers of the VOAG data represented by that line.

have depolarizations greater than this threshold. However, since aerosols with sizes above $1.75 \mu \mathrm{m}$ diameter are physically removed from the sample upstream of the CFDC chamber, the combined consideration of size and depolarization may prove a robust strategy for avoiding the miscounting of aerosols as INP as further discussed below.

In Fig. 3c, the percent of particles that achieve a depolarization ratio $\geq 0.3$ (the nominal selection criteria for depolarizing ice crystals) as a function of particle diameter is shown. In Fig. 3c, the droplet training data collected for all sizes of olive oil droplets are combined and displayed as one line for simplicity. In contrast to the size distributions (Fig. 3a), in which the training datasets cannot be discriminated, the depolarization ratio distributions show notable differences between droplets, aerosols, and ice crystals. Figure $3 \mathrm{~b}$ and c reveal that only $0.3 \%$ of droplets and $1.6 \%$ of aerosol particles achieve a depolarization ratio $\geq 0.3$. The exception to this is aerosols with diameters of 5 to $10 \mu \mathrm{m}$. In this size range, $3.9 \%$ of aerosols achieve a depolarization ratio of 0.3 .
However, 5 to $10 \mu \mathrm{m}$ particles are not abundant in nature, cannot easily be sampled by real-time instruments with the inlet complexity of a CFDC, and only represent $0.3 \%$ of the aerosol training dataset. Furthermore, particles in this size range were not generated during the FIN-02 campaign. In contrast, $13.5 \%$ of particles in the ice crystal training dataset achieve a depolarization ratio of at least 0.3 . This natural break in the depolarization ratio distributions can be considered as a threshold for which particles above the threshold are ice. Below the threshold, the identity of particles is unknown since the majority of all three populations have depolarization ratios between 0 and 0.3 .

\subsection{Determining WDBT conditions in CFDC runs}

As discussed in Sect. 2.4, WDBT can be difficult to identify when relying on the traditional analysis method. To better determine periods when WDBT conditions are occurring in the CFDC, particle size distributions and mean depolarization ratio can be considered. Here, the onset of water droplet breakthrough is analytically defined as the time period where a continuous size distribution extends from the small size bins past the $2 \mu \mathrm{m}$ threshold. For example, we consider a CFDC run from the FIN-02 campaign where Snomax ${ }^{\circledR}$ aerosols were generated by atomization of suspensions and introduced to the AIDA chamber at concentrations of $\sim 2000 \mathrm{~cm}^{-3}$. The CFDC was operated at $-15^{\circ} \mathrm{C} \pm 1.5^{\circ} \mathrm{C}$ and scanned from low to high $\mathrm{SS}_{\mathrm{w}}$. A time series of the normalized size distribution is shown in Fig. 4a. Figure $4 \mathrm{~b}$ and $\mathrm{c}$ show the mean depolarization ratio of all particles larger than $2 \mu \mathrm{m}$ and the CFDC supersaturation (with respect to water and with respect to ice), respectively. In addition, Fig. S1 in the Supplement shows the number lognormal size distribution of Snomax ${ }^{\circledR}$ aerosols generated during this sample period. No Snomax ${ }^{\circledR}$ particles greater than $2 \mu \mathrm{m}$ diameter are present. Under normal operating conditions, such as those occurring during 10:45 to 11:55 CET (central European time zone), the size distribution is clearly a bimodal distribution with an aerosol population at diameters of $\sim 0.5$ to $1.5 \mu \mathrm{m}$ and the ice crystal population at diameters of $\sim 3$ to $25 \mu \mathrm{m}$. In Fig. 4, water droplet breakthrough is observed between 11:55 and 12:15 CET as the upper limit of the CASPOL size distribution increases from 1.5 to $\sim 10 \mu \mathrm{m}$.

In Fig. 4, the CFDC begins sampling at relatively low supersaturations. During this time period, the few ice crystals nucleate in the chamber as particles are mostly larger than $5 \mu \mathrm{m}$ in diameter (Fig. 4a). Initially, there is a wide range of mean depolarization ratios reported. As more ice crystals begin to grow in the chamber at higher $\mathrm{SS}_{\mathrm{w}}\left(\right.$ at $-3 \% \mathrm{SS}_{\mathrm{w}}$ ), the mean depolarization ratio becomes more uniform, with a range of $\sim 0$ to 0.22 before 10:45 to a range of $\sim 0.09$ to 0.12 after 10:45. These values are similar to, but slightly lower than, the mean depolarization for training dataset ice crystals. Then at 11:55 CET (at $4 \% \mathrm{SS}_{\mathrm{w}}$ ) water droplet breakthrough initiates and the mean depolarization ratio decreases 


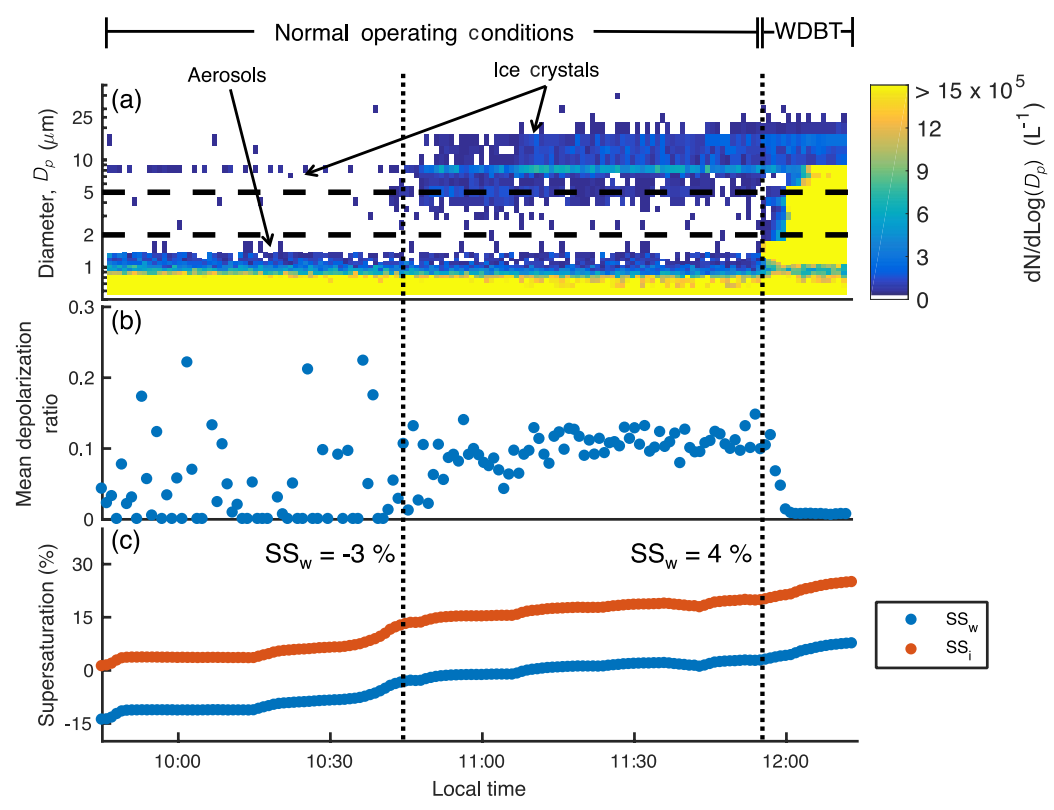

Figure 4. (a) The normalized size distribution, (b) mean depolarization ratio of particles in CFDC with diameter $>2 \mu \mathrm{m}$, and (c) supersaturation conditions with respect to ice $\left(\mathrm{SS}_{\mathrm{i}}\right)$ and water $\left(\mathrm{SS}_{\mathrm{W}}\right)$ for a Snomax ${ }^{\circledR}$ scan on $27 \mathrm{March}$ at $-15^{\circ} \mathrm{C} \pm 1.5^{\circ} \mathrm{C}(\mathrm{case}$ no. 27 in Table 1$)$. The dashed lines in the figure denote the onset of abundant ice nucleation (10:45) and the onset of WDBT (11:55).

to approximately zero, consistent with the theoretical depolarization ratio of water droplets. This is similar to the low mean depolarization ratio of training dataset droplets. Taken together, these results show that the mean depolarization ratio of particles larger than $2 \mu \mathrm{m}$ has a strong dependence on whether or not WDBT is occurring in the CFDC. This makes the mean depolarization ratio a useful tool for confirmation of the onset of water droplet breakthrough.

\subsection{Optical properties of particles present in the CFDC}

In this section, the frequency distribution of depolarization ratios of particle populations present in the CFDC are investigated for comparison to the training datasets. First, all data from the FIN-02 campaign were classified as WDBT conditions or normal operating conditions. Then particle diameters were used to determine the particle type. Aerosol particles during the FIN-02 campaign were generally smaller than $2 \mu \mathrm{m}$ in size. Since water droplets can bias this population during WDBT conditions, only those particles smaller than $2 \mu \mathrm{m}$ in diameter during normal operating conditions are defined as aerosols. Particles $\geq 2 \mu \mathrm{m}$ in diameter during normal operating conditions are identified as ice crystals. A third population is defined as "WDBT particles" and consists of particles $\geq 2 \mu \mathrm{m}$ in diameter during WDBT conditions. This population typically consists of mostly water droplets but can also include ice crystals. These three populations are referred to as "CFDC populations" in this paper.

Figure 5 shows the depolarization ratio distributions of the CFDC populations interpreted to be ice crystals, water droplets, and aerosols. For the analysis completed to produce Fig. 5, 19 normal operating condition periods and 17 WDBT periods with variable time lengths were classified. Ice crystals achieve higher depolarization ratios than water droplets and aerosol; $13.5 \%$ of ice crystals in the CFDC achieve a depolarization ratio larger than 0.3 , compared to $1.5 \%$ percent of water droplets and $0.3 \%$ of aerosols. These values are very similar to the percentages of training data particles that achieve a depolarization ratio greater than 0.3 . Ice crystals achieve depolarization ratios larger than 0.3 more than 10 times more frequently than aerosol or water droplets. One interesting feature in the CFDC observations are the two Snomax ${ }^{\circledR}$ cases (cases 13 and 14 in Table 1 at -33 and $-21{ }^{\circ} \mathrm{C}$, respectively) in Fig. 5. More particles with high depolarization ratios were observed than during the other 15 WDBT cases. These particles are most likely ice crystals. Since Snomax ${ }^{\circledR}$ bacteria are a particularly active INP it is not surprising that ice crystals dominate the population of particles in the CFDC even during WDBT (Wex et al., 2015), particularly for runs with lower temperatures.

\subsection{Comparing CASPOL observations to model calculations}

In this section, modeled and observed particles discussed in the preceding results section are compared. Figure 6 shows modeled and observed mean depolarization ratios of particles as a function of diameter. The modeled results (green) are shown with the same shape conventions as Fig. 2. Observed results include training (blue shapes) and CFDC (red 
Table 1. Date and time (CET), the composition of aerosol sampled, and the CFDC operating temperature $\left( \pm 1.5^{\circ} \mathrm{C}\right)$.

\begin{tabular}{llllr}
\hline Case no. & Date and time & Composition & Chamber & Temperature $\left({ }^{\circ} \mathrm{C}\right)$ \\
\hline 1 & 24 Mar 2015 10:13 & Arizona test dust* & AIDA & -25 \\
2 & 24 Mar 2015 11:25 & Arizona test dust* & AIDA & -20 \\
3 & 24 Mar 2015 12:48 & Arizona test dust* & APC & -19 \\
4 & 24 Mar 2015 16:02 & Argentinian soil dust* & AIDA & -19 \\
5 & 24 Mar 2015 17:29 & Argentinian soil dust* & AIDA & -18 \\
6 & 24 Mar 2015 18:28 & Argentinian soil dust* & AIDA & -24 \\
7 & 25 Mar 2015 10:15 & Argentinian soil dust* & AIDA & -25 \\
8 & 25 Mar 2015 11:22 & Argentinian soil dust* & AIDA & -28 \\
9 & 25 Mar 2015 12:35 & Argentinian soil dust* & APC & -28 \\
10 & 25 Mar 2015 16:48 & Arizona test dust* & AIDA & -25 \\
11 & 25 Mar 2015 17:51 & Arizona test dust* & AIDA & -28 \\
12 & 19 Mar 2015 17:45 & Arizona test dust & AIDA & -34 \\
13 & 20 Mar 2015 11:49 & Snomax ${ }^{\circledR}$ & APC & -33 \\
14 & 20 Mar 2015 13:28 & Snomax ${ }^{\circledR}$ & APC & -21 \\
15 & 21 Mar 2015 10:28 & Snomax ${ }^{\circledR}$ & AIDA & -16 \\
16 & 21 Mar 2015 11:12 & Snomax ${ }^{\circledR}$ & AIDA & -19 \\
17 & 21 Mar 2015 11:47 & Snomax ${ }^{\circledR}$ & AIDA & -20 \\
18 & 21 Mar 2015 12:54 & Snomax ${ }^{\circledR}$ & APC & -15 \\
19 & 23 Mar 2015 10:55 & K-feldspar (contaminated with Snomax $\left.{ }^{\circledR}\right)$ & AIDA & -30 \\
20 & 23 Mar 2015 16:48 & K-feldspar (contaminated with Snomax & AIDA & -25 \\
21 & 23 Mar 2015 18:17 & K-feldspar (contaminated with Snomax $\left.{ }^{\circledR}\right)$ & AIDA & -21 \\
22 & 26 Mar 2015 10:05 & Illite NX & AIDA & -25 \\
23 & 26 Mar 2015 11:09 & Illite NX & AIDA & -25 \\
24 & 26 Mar 2015 12:04 & Illite NX & AIDA & -28 \\
25 & 26 Mar 2015 12:44 & Illite NX & AIDA & -30 \\
26 & 26 Mar 2015 16:39 & Desert dust & APC & -29 \\
27 & 27 Mar 2015 10:59 & Snomax ${ }^{\circledR}$ & APC & -16 \\
\hline
\end{tabular}

* Data collected during "blind tests". Sample composition was provided by the referees after the experiment was completed.

shapes) ice crystals (pentagrams), aerosols (squares), and droplets/WDBT particles (circles). Observed values are accompanied by error bars representing the standard deviation of depolarization ratios of particles at the respective diameters plotted. The CFDC populations presented here include particles sampled from all FIN-02 experiments, and not only those discussed in Sect. 3.5 above. The same conventions are used here to process these particles: CFDC ice crystals are those larger than $2 \mu \mathrm{m}$ sampled under normal operating conditions; CFDC aerosols are those smaller than $2 \mu \mathrm{m}$ sampled under normal operating conditions; and CFDC WDBT particles are those larger than $2 \mu \mathrm{m}$ sampled under WDBT conditions.

In Fig. 6, both the model calculations and the observed results indicate that ice crystals have higher mean depolarization ratios than water droplets and aerosols on average at diameters above $5 \mu \mathrm{m}$. However, error bars show that the standard deviations of depolarization ratios at these sizes are very large and that differences in the mean depolarization ratios of the observed particles displayed are not statistically significant. This represents a major challenge in designing a new analysis method that uses depolarization ratio to quantify INP.

In Sect. 3.5, the complex WDBT population was discussed. WDBT particles consist of both water droplets and ice crystals. Diffusional growth theory dictates that ice crystals will grow to larger sizes in the CFDC than water droplets (Pruppacher and Klett, 2010). Figure 6 shows an increase in the depolarization ratio from $\sim 0$ to 0.25 in the CFDC WDBT population starting at $\sim 6 \mu \mathrm{m}$. At diameters greater than $10 \mu \mathrm{m}$ the mean depolarization ratio of WDBT particles is greater than or equal to the depolarization of CFDC ice crystals and training dataset ice crystals, suggesting that these large particles are mostly or all ice crystals. It is inferred that particles in the 6 to $10 \mu \mathrm{m}$ range are a mixture of water droplets and ice crystals.

There are significant differences between modeled particles and their observed counterparts. Observations show water droplets depolarizing light, but the observed mean depolarization ratio of water droplets is almost zero $(\delta \leq 0.05)$. Another significant difference is that for both ice crystals and aerosols, the mean observed depolarization ratios are approximately $30 \%$ lower than the modeled depolarization ratio. 


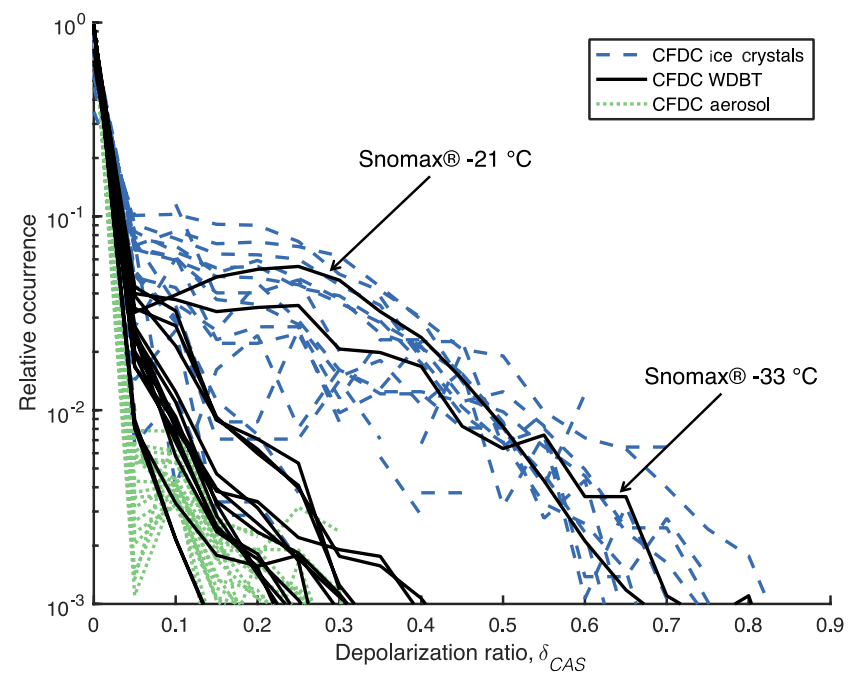

Figure 5. Frequency distribution of depolarization ratios for CFDC populations: ice crystal periods (19 periods classified), WDBT periods (17 periods classified), and aerosol periods (19 periods classified). Mean temperatures of periods included range from -15 to $-35^{\circ} \mathrm{C}$.

One possible reason for the discrepancies between the model and observations is that the CASPOL depolarization detector underestimates the depolarization of particles due to the weak depolarization of particles and relatively high detection limit of the CASPOL perpendicularly polarized detector. In general, particles scatter relatively little perpendicularly polarized light in the backward 1 raw count, which translates roughly to a scattering cross section of $\sim 1 \times 10^{-13} \mathrm{~cm}^{2}$. This limit results in the CASPOL registering a perpendicular signal below CASPOL's detection limit for $45 \%$ of training ice crystals, $76 \%$ of training aerosols, and $57 \%$ of training droplets. In the training datasets, all particles with undetected perpendicularly polarized detector were assigned depolarization ratio of zero. Another possibility is that the idealized model particles do not accurately depict the shape, composition, or other microphysical properties of the observed particles. Smith et al. (2016) found that after an ice crystal has nucleated, the geometry of the ice crystal can be modified leading to drastic differences in the observed depolarization ratio. To investigate this, Smith et al. (2016) operated the Manchester Ice Cloud Chamber at different temperatures and supersaturations to produce an assortment of ice crystal morphologies including solid and hollow columns, plates, sectored plates, and dendrites. During that study, they also compared observed and modeled depolarization ratio results and found that on average the difference between modeled and observed depolarization ratios was $\sim 120 \%$. The CFDC results reported in Fig. 6 include data from all of the runs sampled during FIN-02. The dataset of the campaign represents ice nucleation events over a broad range of temperature $(-15$ to $\left.-35^{\circ} \mathrm{C}\right)$ and supersaturation $\left(0\right.$ to $\left.40 \% \mathrm{SS}_{\mathrm{i}}\right)$ conditions.
Thus, many different habits of ice crystals likely formed in the CFDC, in part, contributing to the wide range of depolarization ratios reported in Fig. 6. Nicolet et al. (2007) reported modeling results of single particles that confirm that a wide range of depolarization ratios can be detected for a single shape depending on the orientation. Non-preferential orientation of particles in the CFDC is likely to contribute to the breadth of depolarization ratios detected.

The observations are qualitatively consistent with the model in that ice crystals depolarize more light than water droplets and aerosols. However, the discrepancies between the observed and modeled mean depolarization ratios and the wide distributions of observed depolarization ratios dictate that we cannot rely on a mean modeled depolarization ratio to identify and quantify ice crystals in the CFDC. Rather than designing a theoretical model based on model calculations, we move forward by designing an empirical model based on the CASPOL observed signals.

\subsection{Designing an empirical model to quantify INP with depolarization ratio}

The results above show that counting ice crystals in the CFDC using depolarization ratio can be challenging since only $\sim 13.5 \%$ of ice crystals achieve a depolarization ratio greater than 0.3 (Fig. 3). A depolarization ratio threshold of 0.3 is a favorable criterion to detect ice crystals because less than $2 \%$ of the water droplets and aerosols achieve this depolarization ratio. However, when there are extreme concentrations of water droplets, such as those experienced during water droplet breakthrough conditions, the water droplet concentration may be $10^{3}$ times greater than the ice crystal concentration in the CFDC, effectively reducing the signal (ice crystals) to noise (water droplets with $\delta \geq 0.3$ ) ratio $\sim 1: 1$ or worse. Therefore, an INP concentration cannot be determined by simply applying a depolarization ratio criterion to detect ice crystals with the CFDC-CASPOL.

To obtain a more accurate INP concentration, we used a linear regression model to fit the number of particles with depolarization ratios above the threshold (0.3) to the number of ice crystals in the CFDC. Linear regressions are frequently used to interpret the signal(s) of new instrumentation or new techniques by validating the signal with a "ground truth" measurement (e.g., Li et al., 2016; Zimmerman et al., 2017; Brunner et al., 2016; Choi et al., 2016).

In our case, ground truth is provided by the aerosolonly (Storm Peak), ice-only (homogeneous), and dropletonly (VOAG) training data populations discussed above. To create a linear regression model which relates the number of particles with depolarization ratios above the threshold $(0.3)$ to ice crystals concentration, a CASPOL dataset containing a known number of ice crystal and non-ice particles is required. Here, aerosol-only, ice-only, and droplet-only data are added together to create artificial datasets in which the number of each type of particle is known. The aerosol, ice 


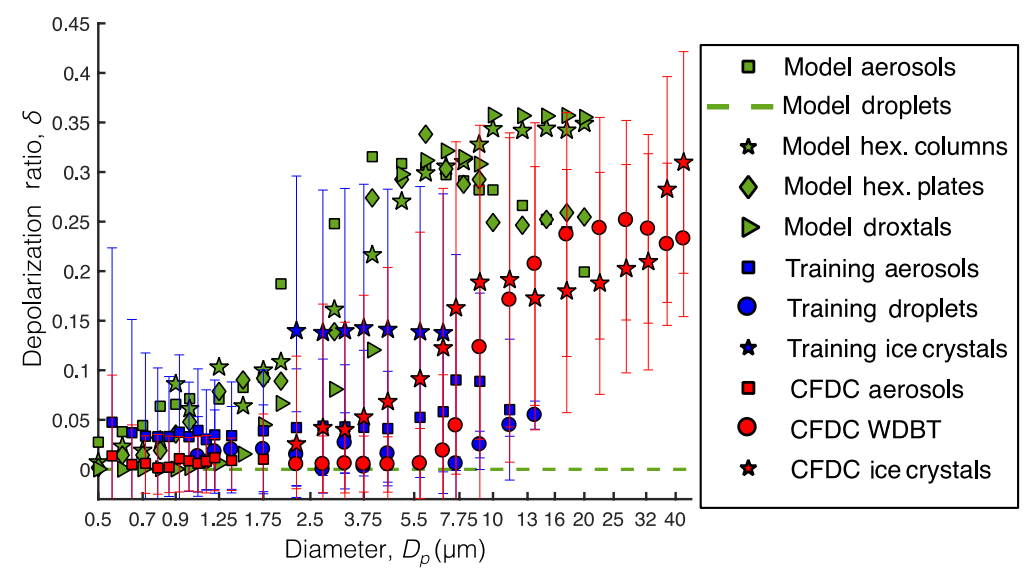

Figure 6. Mean depolarization ratios vs. particle diameter for modeled and observed particles. Observed error bars provide a standard deviation on the depolarization ratios of particles at each reported size. No error bars are reported for model calculations.

crystal, and droplet training datasets are randomized in time before particles are selected from each population to create the simulated datasets. (This analysis is possible because the data point for each individual particle detected by the CASPOL includes forward scattering, backward scattering, and depolarization).

In total 50 simulated datasets are generated. Table $\mathrm{S} 1$ in the Supplement 50 the concentration of ice crystals, water droplets, and aerosols in each dataset. Each simulated dataset is divided into 120 segments, containing a number of ice crystals ranging from 0 to 350 . The number of water droplets and aerosols are constant throughout all segments in a single dataset. All 50 datasets contain segments with the same number of randomly selected ice crystals. The upper range of $M$ values here represents an extreme sampling condition where there are many aerosols and many cloud condensation nuclei that will form cloud droplets, but few INP. Given the relatively high number of aerosols and droplets, this would represent the most challenging sampling scenario for proposed new method.

The quantity of aerosols and water droplets in each dataset is determined by a multiplication factor $M$, such that the number of water droplets $=100 \mathrm{M}$ and the number of aerosols $=300 M$. For example, the first simulated dataset $(M=1)$ contains 100 water droplets and 300 aerosols. For each iteration, $M$ is increased by 1 . In summary, 50 datasets were generated, containing 100 to 5000 water droplets and 300 to 15000 aerosol particles.

As discussed above, particles in the INP datasets smaller than the CFDC size cut of $2 \mu \mathrm{m}$ diameter were removed. Next, for each of the 120 segments in the simulated dataset, the number of particles with a depolarization ratio greater than or equal to a selected depolarization ratio threshold (ranging from 0 to 0.75 in increments of 0.05 ) is determined. A linear fit is determined for the relationship between the known ice crystal concentration and the number of parti-

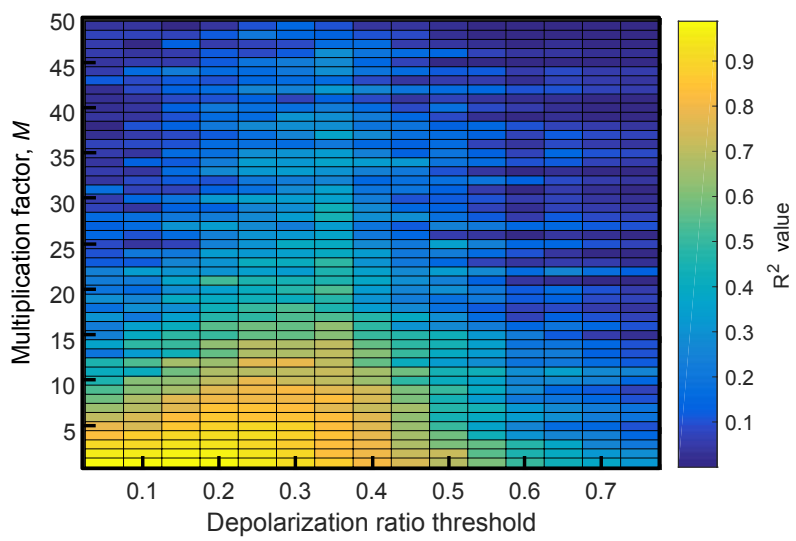

Figure 7. $R^{2}$ values for linear regression fit as a function of depolarization ratio threshold for optimizing ice crystal differentiation and water droplet and/or aerosol concentration multiplication factor, $M$.

cles detected greater than or equal to the depolarization ratio threshold for the first dataset $(M=1)$. The linear regression fit is applied to all of the simulated datasets over the entire range of $M$. Only one fit is determined for each threshold because we cannot feasibly design a model that adapts to water droplet and aerosol concentration in the CFDC An $R^{2}$ value is determined to assess the goodness of the linear regression fit over all of the simulated datasets.

Figure 7 shows the $R^{2}$ values as a function of $M$ and depolarization ratio threshold for each of the simulated datasets. The figure reveals that high choices of depolarization ratio thresholds perform poorly because very few particles will achieve a high depolarization ratio. In contrast, the figure shows that $R^{2}$ values are quite high for cases where aerosol and droplet concentrations are low and the depolarization ratio threshold is low. However, as the concentration of droplets and aerosol increase, the $R^{2}$ value for a given threshold de- 


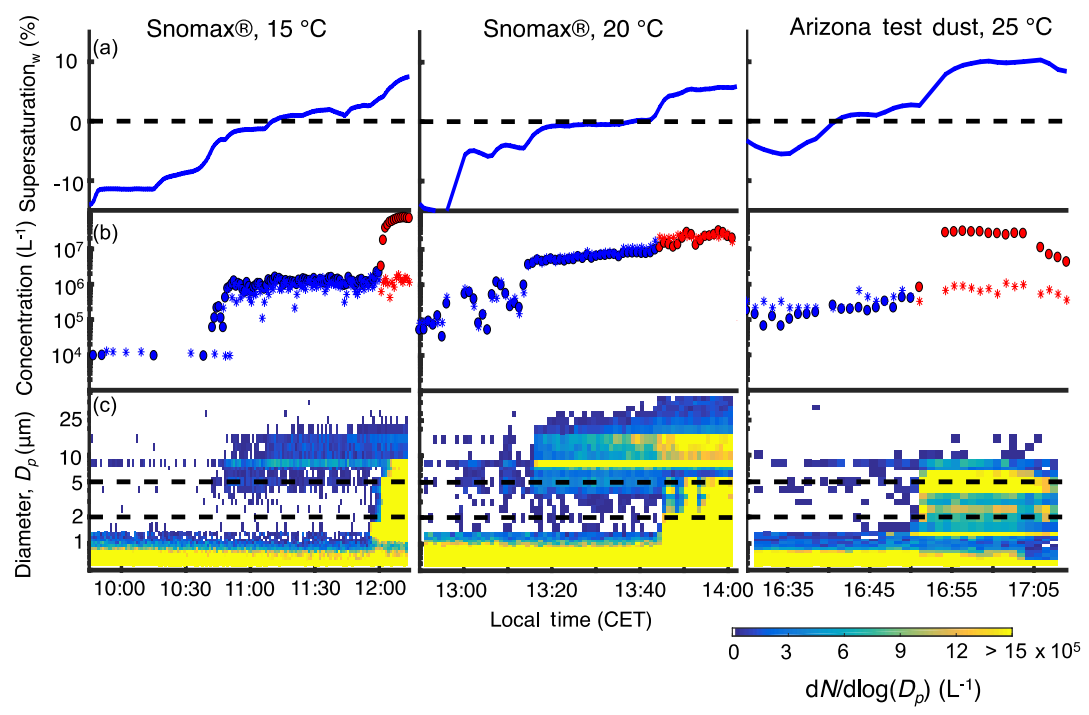

Figure 8. Application of depolarization ratio method on three CFDC runs. Aerosol composition and temperature are labeled in the title. (a) Time series of supersaturation with respect to water. (b) INP concentrations under normal (blue) and WDBT (red) conditions are shown for the traditional (circle) and new (asterisk) analysis methods. (c) The normalized number distributions of all particles detected by the CASPOL. Time is reported in local time (CET).

creases. This is especially true for lower depolarization ratio thresholds that are more sensitive to increases in droplets and aerosols. An optimal choice for depolarization ratio threshold is defined as a threshold that retains high $R^{2}$ values across the entire range of $M$. The threshold should be sufficiently high that it is not sensitive to water droplets and aerosols that may be highly depolarizing and sufficiently low that particles are still detected. Figure 7 shows that a threshold value of 0.35 out performs all other thresholds when $M$ is larger than 20 , including our initial visually chosen threshold value of 0.3 . The mean $R^{2}$ value for the 0.35 threshold is 0.46 . The next best performing threshold is 0.3 with a mean $R^{2}$ value of 0.44 . However, aerosol and water droplet concentrations in CFDC experiments are typically in the range of $1<M<20$. The mean $R^{2}$ value in this range of $M$ for the 0.3 and 0.35 thresholds 0.71 and 0.7 , respectively. While the performance of these thresholds perform comparably over this range, we selected the 0.3 threshold because it will slightly outperform the 0.35 threshold, especially when detecting lower INP concentrations.

The linear regression for the 0.3 threshold is provided in Eq. (9):

$N_{\mathrm{INP}}=6.11 N_{\delta}+22.20$,

where $N_{\delta}$ is the number of particles that have a depolarization ratio greater than 0.3 and $N_{\text {INP }}$ is the derived INP number. Next, Eq. (9) is applied to all CFDC-CASPOL data collected during the FIN-02 campaign and the accuracy of this model is assessed.

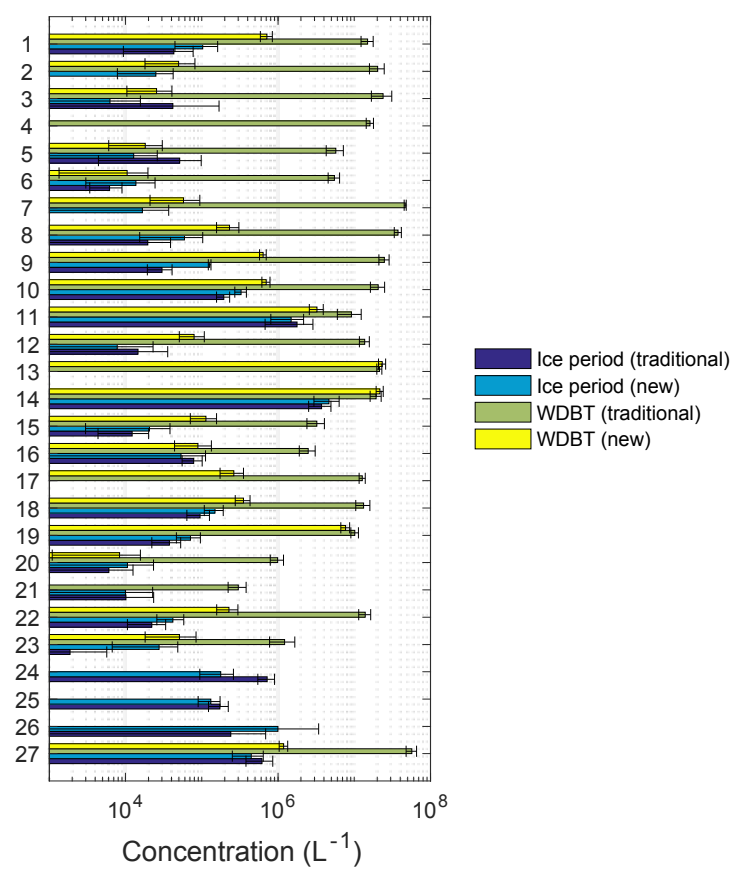

Figure 9. Individual cases of "ice-only" and "WDBT" INP concentration comparisons with the traditional size cut and depolarization ratio methods. Error bars report the CFDC-CASPOL counting error of $39 \%$. 


\subsection{Application of the new analysis method to CFDC data collected during FIN-02}

INP concentrations were obtained using both the depolarization ratio method (Eq. 9) and the traditional method on CFDC data collected during the FIN-02 campaign. Three representative CFDC runs of Snomax ${ }^{\circledR}$ at $-15^{\circ} \mathrm{C}$ and at $-20^{\circ} \mathrm{C}$ and Arizona test dust at $-25^{\circ} \mathrm{C}$ are shown in Fig. 8 . Each humidity scan starts in subsaturated conditions with respect to water. Supersaturation is gradually increased until ice nucleation initiates and then further increased until WDBT occurs (represented by the red symbols in Fig. 8). The reported concentrations reveal that the traditional (circles) and depolarization ratio (*) methods generally agree during "ice-only" periods (blue symbols in Fig. 8). In most cases there is clear disagreement between concentrations in WDBT periods, for example in the cases of Snomax ${ }^{\circledR}$ at $-15^{\circ} \mathrm{C}$ and Arizona test dust at $-25^{\circ} \mathrm{C}$. This is expected since the traditional concentration is sensitive to an increase in water droplets that grow larger than the size cut applied in WDBT conditions, where INP concentrations are usually not reported. An exception to this can be seen in Fig. 8b, the Snomax ${ }^{\circledR}$ at $-20^{\circ} \mathrm{C}$. The concentrations from the two methods remain in good agreement as the supersaturation is increased into the WDBT period. In this case, the ice crystal concentration is dominating the population in WDBT. The evidence for this is the high concentration of ice crystals that from 13:15 CET as observed in the size distribution time series in center panel Fig. 8b.

Figure 9 summarizes the mean concentrations obtained through the traditional and new method for all periods when the CFDC was operational during FIN-02. In total, 27 iceonly periods and WDBT cases are included. A description of the date and time, aerosol composition, and temperature of each case is detailed in Table 1 . In cases 24, 25, and 26 WDBT did not occur, so no data are reported. The error bars report the CFDC-CASPOL uncertainty in INP concentration, which is $39 \%$ based on combined instrumental uncertainties (Glen and Brooks, 2014, 2013), Fig. 9 shows that in all but 4 cases out of 27 (cases 2, 7, 9, and 23), the mean concentration of the new analysis method is in agreement with traditional analysis method for the ice-only periods. Figure 9 also shows that only 9 out of 24 WDBT cases have statistical agreement between the new and traditional analysis method. At the onset of WDBT, the impact of water droplets on the INP concentration determined by the $2 \mu \mathrm{m}$ size cut may not be very large and the concentration may closely resemble the true INP concentration, but as the $\mathrm{SS}_{\mathrm{w}}$ is increased more water droplets will be incorrectly counted in the traditional INP concentration. This phenomenon gives rise to the large error bars reported in some of the WDBT cases. In general, the observations reported in Fig. 9 are consistent with the assertion that the traditional method and new method are in agreement during the ice-only periods and that during WDBT the traditional method is elevated in response to large water droplets

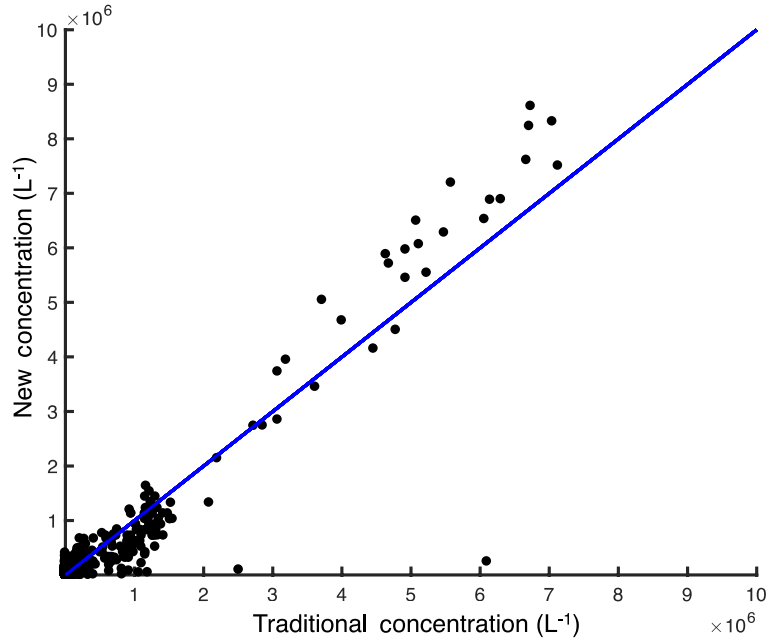

Figure 10. Traditional INP concentration vs. new INP concentration with $1: 1$ line for "ice-only" periods.

miscounted as INP while the depolarization ratio method remains accurate.

To summarize the comparison between our new method and the traditional method during the ice-only periods, the INP concentrations determined using the traditional method vs. new method are plotted in Fig. 10. Each point on the plot represents data for a $1 \mathrm{~min}$ segment. The black line in Fig. 10 is a 1:1 line. Since the analysis used to generate Fig. 10 only uses data collected under normal operating conditions (not WDBT), the traditional concentration can be considered ground truth. The data closely follow the $1: 1$ line, confirming that the depolarization ratio can be used to reliably retrieve an INP concentration when no or few water droplets and/or aerosols are larger than $2 \mu \mathrm{m}$. To assess the performance of the new method we use mean percent error (MPE) defined here as

MPE $=\frac{\text { new concentration }- \text { traditonal concentration }}{\text { traditional concentration }} \times 100 \%$.

The MPE of the method is dependent on the INP concentration. Due to the high detection limit of concentration for the CASPOL, the MPE of the new method is $\pm 500 \%$ when the traditional concentration is between 0 and $50000 \mathrm{~L}^{-1}$. However, at higher concentrations the MPE is typically $\pm 50 \%$ or less. Additionally, Fig. 10 shows that at concentrations in the range of 0 to $3 \times 10^{6} \mathrm{~L}^{-1}$, the new method typically undercounts INPs but overcounts INPs at higher concentrations (greater than $3 \times 10^{6} \mathrm{~L}^{-1}$ ). The MPE for the new method for all concentrations is $\pm 32.1 \%$.

Based on Fig. 10, the new analysis method provides very accurate results when INP concentrations are greater than $50000 \mathrm{~L}^{-1}$, which is only achievable in laboratory settings. For this reason, the method is not suitable to be used in a field setting where concentrations typically range from 0.1 to 


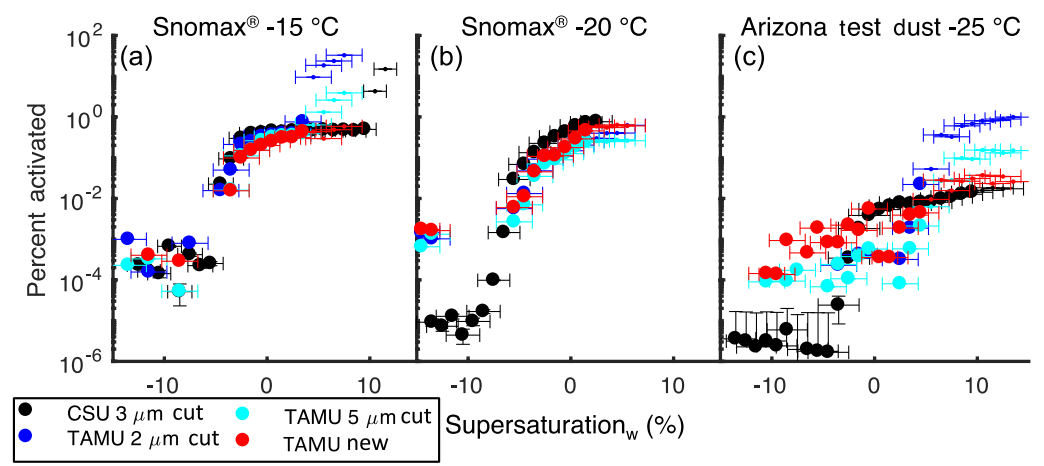

Figure 11. TAMU CFDC versus CSU CFDC comparison: (a) Snomax ${ }^{\circledR}$ at $-15^{\circ} \mathrm{C}$, (b) Snomax ${ }^{\circledR}$ at $-20^{\circ} \mathrm{C}$, and (c) Arizona test dust at $-25^{\circ} \mathrm{C}$. Small symbols indicate that those points were sampled in WDBT. TAMU $2 \mu \mathrm{m}$ cut and $5 \mu \mathrm{m}$ cut traditional activated INP fraction are shown in blue and cyan, respectively. The TAMU new analysis method activated INP fraction is shown in red. The CSU $3 \mu \mathrm{m}$ INP fraction activated is shown in black.

$100 \mathrm{~L}^{-1}$ (e.g., Mason et al., 2016; Jiang et al., 2014; DeMott et al., 2003; Kanji et al., 2017). Nonetheless, the new method is considered an improvement for use during water droplet breakthrough, when the traditional method cannot be used.

As a final test of the new method during water droplet breakthrough periods, a reliable measure of INP at higher supersaturation conditions (when the TAMU CFDC is experiencing WDBT) is needed. Due to design and flow rate differences, the CSU CFDC does not experience the onset of WDBT until higher supersaturations than the TAMU CFDC, up to $108 \%$ or higher depending on temperature (DeMott et al., 2015). Thus, inclusion of the CSU data provides a test of the new method at higher relative humidities under conditions when data obtained through the TAMU CFDC's traditional method is spurious due to water droplet breakthrough. Figure 11 shows the comparison of the TAMU CFDC's traditional $(2 \mu \mathrm{m}$ size cut $)$ and new method INP concentrations and the CSU CFDC INP concentration, collected during the FIN-02 campaign. Because CASPOL sizing of nonspherical ice crystals nucleated and grown in the chamber is uncertain, the data were also analyzed using a $5 \mu \mathrm{m}$ size cut to provide an estimate of the lower limit of INP concentration. As discussed above, the CSU CFDC has a longer chamber, a different evaporation region design, a different detector, and a chosen size cut of $3 \mu \mathrm{m}$. Results of INP percent activated are reported from three CFDC runs discussed earlier including Snomax ${ }^{\circledR}$ at -15 and $-20^{\circ} \mathrm{C}$ and Arizona test dust at $-25^{\circ} \mathrm{C}$. Concentrations used to calculate the percent activation are average concentrations of samples in a $1 \%$ range of $\mathrm{SS}_{\mathrm{w}}$ conditions in the CFDC. Large symbols show data collected under normal operating conditions. Small symbols show data collected during WDBT conditions in the TAMU CFDC. The CSU CFDC did not experience WDBT in the data reported in Fig. 11. The traditional concentration from TAMU and CSU and the new method concentration all are in reasonable agreement during ice-only conditions for all three cases. During WDBT, the TAMU traditional concen- trations increase in response to the water droplets that grow larger than the size criteria ( 2 or $5 \mu \mathrm{m})$. Fortunately, the new method remains in agreement with the CSU concentration. Figure $11 \mathrm{~b}$ shows the special case of high activation of INP shown in Fig. 8b. This case involves a highly active INP, Snomax ${ }^{\circledR}$ at $-20^{\circ} \mathrm{C}$, a significantly colder temperature than required for the Snomax ${ }^{\circledR}$ to activate as INP. Since most particles activated prior to the onset of WDBT, there is negligible difference in the concentrations reported during ice-only and WDBT periods. In conclusion, the new method accurately determines the INP concentration in the presence of water droplets and can thus extend the range of operating conditions of the TAMU CFDC.

\section{Conclusions}

This paper presents a new analysis method that uses the depolarization ratio to quantify INP concentrations in the TAMU CFDC in terms of single-particle depolarization measured by the CFDC's CASPOL detector. Ice crystal, droplet and aerosol training populations were used to build simulated datasets with known concentrations of aerosols, droplets, and ice crystals, respectively. The simulated datasets were evaluated, assuming a depolarization ratio threshold of 0.3 , above which all particles were classified as ice crystals. A linear regression fit between ice crystal concentration and number of particles detected greater than or equal to the depolarization ratio threshold of 0.3 was determined and applied to CFDC data collected during the FIN-02 campaign. Concentrations of INP determined by the new analysis method agree reasonably well with the traditional method (ice detection by size segregation) under normal operating temperatures and supersaturations (with no large water droplets present) with a mean percent error of $\pm 32.1 \%$. While high INP concentrations of $10^{4}$ to $10^{6} \mathrm{~L}^{-1}$ can be generated in laboratory settings, typical ambient INP concentrations range from 0 to $100 \mathrm{~L}^{-1}$. 
For this reason, the new CASPOL depolarization method is recommended for CFDC laboratory experiments only. A comparison between the CSU CFDC INP concentration and TAMU CFDC INP concentration derived from the new analysis method show agreement even under conditions in which the TAMU CFDC experiences WDBT and CSU does not experience WDBT. We conclude that the new method can be used to extend the range of operating conditions in the CFDC. However, under conditions encountered in field studies, the traditional method is still preferred analysis method for counting ice nucleating crystals with the TAMU CFDC.

Data availability. The data used in this study will be made available in a future publication (DeMott et al., 2017).

\section{The Supplement related to this article is available online at https://doi.org/10.5194/amt-10-4639-2017-supplement.}

Competing interests. The authors declare that they have no conflict of interest.

Acknowledgements. The authors acknowledge primary support from the National Science Foundation, grant no. ECS-1309854. Ezra J. T. Levin, Kaitlyn J. Suski, and Paul J. DeMott acknowledge support from NSF grant no. AGS-1358495. The FIN-02 and FIN-03 campaigns were supported by NSF grant no. AGS-1339264 and by the US Department of Energy's Atmospheric System Research, an Office of Science, Office of Biological and Environmental Research program, under grant no. DE-SC0014487. Special thanks to Daniel Cziczo and Ottmar Möhler for their roles in coordinating the FIN-02 and FIN-03 studies and to all research teams involved in making those studies possible.

Edited by: Mingjin Tang

Reviewed by: four anonymous referees

\section{References}

Amato, P., Joly, M., Schaupp, C., Attard, E., Möhler, O., Morris, C. E., Brunet, Y., and Delort, A.-M.: Survival and ice nucleation activity of bacteria as aerosols in a cloud simulation chamber, Atmos. Chem. Phys., 15, 6455-6465, https://doi.org/10.5194/acp15-6455-2015, 2015.

Atkinson, J. D., Murray, B. J., Woodhouse, M. T., Whale, T. F., Baustian, K. J., Carslaw K. S., Dobbie S., O'Sullivan, D., and Malkin, T. L.: The importance of feldspar for ice nucleation by mineral dust in mixed-phase clouds, Nature, 498, 355-358, 2013.

Bailey, M. P. and Hallett, J.: A comprehensive habit diagram for atmospheric ice crystals: Confirmation from the laboratory, AIRS II, and other field studies, J. Atmos. Sci., 66, 2888-2899, 2009.
Bi, L. and Yang, P.: Accurate simulation of the optical properties of atmospheric ice crystals with the invariant imbedding T-matrix method, J. Quant. Spectrosc. Ra., 138, 17-35, 2014.

Bi, L., Yang, P., Kattawar, G. W., and Mishchenko, M. I.: Efficient implementation of the invariant imbedding T-matrix method and the separation of variables method applied to large nonspherical inhomogeneous particles, J. Quant. Spectrosc. Ra., 116, 169183, 2013.

Bohren, C. F. and Huffman, D. R.: Absorption and Scattering of Light by Small Particles, Wiley-VCH, Weinheim, Germany, 1983.

Boucher, O., Randall, D., Artaxo, P., Bretherton, C., Feingold, G., Forster, P., Kerminen, V. M., Kondo, Y., Liao, H., Lohmann, U., and Rasch, P.: Clouds and Aerosols, in: Climate Change: The Physical Science Basis. Contribution of Working Group I to the Fifth Assessment Report of the Intergovernmental Panel on Climate Change, Cambridge University Press, Cambridge, UK and New York, NY, USA, 571-657, 2013.

Brooks, S. D., Toon, O. B., Tolbert, M. A., Baumgardner, D., Gandrud B. W., Browell E. V., Flentje, H., and Wilson, J. C.:, Polar stratospheric clouds during SOLVE/THESEO: Comparison of lidar observations with in situ measurements, J. Geophys. Res.Atmos., 109, D02212, https://doi.org/10.1029/2003JD003463, 2004.

Brooks, S. D., Suter, K., and Olivarez, L.: Effects of chemical aging on the ice nucleation activity of soot and polycyclic aromatic hydrocarbon aerosols, J. Phys. Chem. A, 118, 10036-10047, 2014.

Brunner, J., Pierce, R. B., and Lenzen, A.: Development and validation of satellite-based estimates of surface visibility, Atmos. Meas. Tech., 9, 409-422, https://doi.org/10.5194/amt-9409-2016, 2016.

Choi, M., Kim, J., Lee, J., Kim, M., Park, Y.-J., Jeong, U., Kim, W., Hong, H., Holben, B., Eck, T. F., Song, C. H., Lim, J.-H., and Song, C.-K.: GOCI Yonsei Aerosol Retrieval (YAER) algorithm and validation during the DRAGON-NE Asia 2012 campaign, Atmos. Meas. Tech., 9, 1377-1398, https://doi.org/10.5194/amt9-1377-2016, 2016.

Clauss, T., Kiselev, A., Hartmann, S., Augustin, S., Pfeifer, S., Niedermeier, D., Wex, H., and Stratmann, F.: Application of linear polarized light for the discrimination of frozen and liquid droplets in ice nucleation experiments, Atmos. Meas. Tech., 6, 1041-1052, https://doi.org/10.5194/amt-6-1041-2013, 2013.

Collier, K. N. and Brooks, S. D.: Role of organic hydrocarbons in atmospheric ice formation via contact freezing, J. Phys. Chem. A, 120, 10169-10180, 2016.

Coluzza, I., Creamean, J., Rossi, M. J., Wex, H., Alpert, P. A., Bianco, V., Boose, Y., Dellago, C., Felgitsch, L., FröhlichNowoisky, J., Herrmann, H., Jungblut, S., Kanji, Z. A., Menzl, G., Moffett, B., Moritz, C., Mutzel, A., Pöschl, U., Schauperl, M., Scheel, J., Stopelli, E., Stratmann, F., Grothe, H., and Schmale III, D.: Perspectives on the Future of Ice Nucleation Research: Research Needs and Unanswered Questions Identified from Two International Workshops, Atmosphere, 8, 138, https://doi.org/10.3390/atmos8080138, 2017.

Creamean, J. M., Suski, K. J., Rosenfeld, D., Cazorla, A., DeMott, P. J., Sullivan, R. C., White, A. B., Ralph, F. M., Minnis, P., and Comstock, J. M.: Dust and biological aerosols from the Sahara and Asia influence precipitation in the western US, Science, 339, 1572-1578, 2013. 
Cziczo, D. J., Ladino, L., Boose, Y., Kanji, Z. A., Kupiszewski, P., Lance, S., Mertes, S., and Wex, H.: Measurements of Ice Nucleating Particles and Ice Residuals, Meteor. Mon., 58, 8.1-8.13, 2017.

De Boer, G., Morrison, H., Shupe, M., and Hildner, R.: Evidence of liquid dependent ice nucleation in high-latitude stratiform clouds from surface remote sensors, Geophys. Res. Lett., 38, L01803, https://doi.org/10.1029/2010GL046016, 2011.

DeMott, P. J., Sassen, K., Poellot, M.R., Baumgardner, D., Rogers, D. C., Brooks, S. D., Prenni, A. J., and Kreidenweis, S. M.: African dust aerosols as atmospheric ice nuclei, Geophys. Res. Lett., 30, 1732, https://doi.org/10.1029/2003GL017410, 2003.

DeMott, P. J., Möhler, O., Stetzer, O., Vali, G., Levin, Z., Petters, M. D., Murakam, M., Leisner, T., Bundke, U., Klein, H., Kanji, Z., Cotton, R., Jones, H., Petters, M., Prenni, A., Benz, S., Brinkmann, M., Rzesanke, D., Saathoff, H., Nicolet, M., Gallavardin, S., Saito, A., Nillius, B., Bingemer, H., Abbatt, J., Ardon, K., Ganor, E., Georgakopoulos, D. G., and Saunders, C.: Resurgence in ice nucleation research, B. Am. Meteorol. Soc., 92, 1623-1635, 2011.

DeMott, P. J., Prenni, A. J., McMeeking, G. R., Sullivan, R. C., Petters, M. D., Tobo, Y., Niemand, M., Möhler, O., Snider, J. R., Wang, Z., and Kreidenweis, S. M.: Integrating laboratory and field data to quantify the immersion freezing ice nucleation activity of mineral dust particles, Atmos. Chem. Phys., 15, 393-409, https://doi.org/10.5194/acp-15-393-2015, 2015.

DeMott, P. J., Hill, T. C., McCluskey, C. S., Prather, K. A., Collins, D. B., Sullivan, R. C., Ruppel, M. J., Mason, R. H., Irish, V. E., and Lee, T.: Sea spray aerosol as a unique source of ice nucleating particles, P. Natl. Acad. Sci. USA, 113, 5797-5803, 2016.

DeMott, P. J., et al.: Overview of results from the Fifth International Workshop on Ice Nucleation, Part 2 (FIN-02): Laboratory intercomparisons of ice nucleation measurements, Atmos. Chem. Phys. Discuss., in preparation, 2017.

Durant, A. J. and Shaw, R. A.: Evaporation freezing by contact nucleation inside-out, Geophys. Res. Lett., 32, L20814, https://doi.org/10.1029/2005GL024175, 2005.

Fornea, A. P., Brooks, S. D., Dooley, J. B., and Saha, A.: Heterogeneous freezing of ice on atmospheric aerosols containing ash, soot, and soil, J. Geophys. Res.-Atmos., 114, D13201, https://doi.org/10.1029/2009JD011958, 2009.

Garimella, S., Kristensen, T. B., Ignatius, K., Welti, A., Voigtländer, J., Kulkarni, G. R., Sagan, F., Kok, G. L., Dorsey, J., Nichman, L., Rothenberg, D. A., Rösch, M., Kirchgäßner, A. C. R., Ladkin, R., Wex, H., Wilson, T. W., Ladino, L. A., Abbatt, J. P. D., Stetzer, O., Lohmann, U., Stratmann, F., and Cziczo, D. J.: The SPectrometer for Ice Nuclei (SPIN): an instrument to investigate ice nucleation, Atmos. Meas. Tech., 9, 2781-2795, https://doi.org/10.5194/amt-9-2781-2016, 2016.

Glen, A.: The development of measurement techniques to identify and characterize dusts and ice nuclei in the atmosphere, Diss., Texas A\&M University, 2014.

Glen, A. and Brooks, S. D.: A new method for measuring optical scattering properties of atmospherically relevant dusts using the Cloud and Aerosol Spectrometer with Polarization (CASPOL), Atmos. Chem. Phys., 13, 1345-1356, https://doi.org/10.5194/acp-13-1345-2013, 2013.
Glen, A. and Brooks, S. D.: Single particle measurements of the optical properties of small ice crystals and heterogeneous ice nuclei, Aerosol Sci. Tech., 48, 1123-1132, 2014.

Hecht, E. and Zajac, A.: Optics 4th (International) edition, Addison Wesley Publishing Company, 2002.

Hoose, C. and Möhler, O.: Heterogeneous ice nucleation on atmospheric aerosols: a review of results from laboratory experiments, Atmos. Chem. Phys., 12, 9817-9854, https://doi.org/10.5194/acp-12-9817-2012, 2012.

Hu, Y., Winker, D., Vaughan, M., Lin, B., Omar, A., Trepte, C., Flittner, D., Yang, P., Nasiri, S. L., and Baum, B.: CALIPSO/CALIOP cloud phase discrimination algorithm, J. Atmos. Ocean Tech., 26, 2293-2309, 2009.

Jiang, H., Yin, Y., Yang, L., Yang, S., Su, H., and Chen, K.: The characteristics of atmospheric ice nuclei measured at different altitudes in the Huangshan Mountains in Southeast China, Adv. Atmos. Sci., 31, 396-406, 2014.

Johnson, B. R.: Invariant imbedding T matrix approach to electromagnetic scattering, Appl. Optics, 27, 4861-4873, 1988.

Kanji, Z. A., Ladino, L., Wex, H., Boose, Y., Burkert-Kohn, M., Cziczo, D. J., and Krämer, M.: Overview of Ice Nucleating Particles, Meteor. Mon., 58, 1.1-1.33, 2017.

Koepke, P., Gasteiger, J., and Hess, M.: Technical Note: Optical properties of desert aerosol with non-spherical mineral particles: data incorporated to OPAC, Atmos. Chem. Phys., 15, 59475956, https://doi.org/10.5194/acp-15-5947-2015, 2015.

Korolev, A.: Limitations of the Wegener-Bergeron-Findeisen mechanism in the evolution of mixed-phase clouds, J. Atmos. Sci., 64, 3372-3375, 2007.

Levin, E., McMeeking, G., DeMott, P., McCluskey, C., Carrico, C., Nakao, S., Jayarathne, T., Stone, E., Stockwell, C., and Yokelson, R.: Ice-nucleating particle emissions from biomass combustion and the potential importance of soot aerosol, J. Geophys. Res.Atmos., 121, 5888-5903, 2016.

Li, S., Joseph, E., and Min, Q.: Remote sensing of ground-level $\mathrm{PM}_{2.5}$ combining AOD and backscattering profile, Remote Sens. Environ., 183, 120-128, 2016.

Linke, C., Möhler, O., Veres, A., Mohácsi, Á., Bozóki, Z., Szabó, G., and Schnaiter, M.: Optical properties and mineralogical composition of different Saharan mineral dust samples: a laboratory study, Atmos. Chem. Phys., 6, 3315-3323, https://doi.org/10.5194/acp-6-3315-2006, 2006.

Liu, C., Panetta, R. L., Yang, P., Macke, A., and Baran, A. J.: Modeling the scattering properties of mineral aerosols using concave fractal polyhedra, Appl. Optics, 52, 640-652, 2013.

Mason, R. H., Si, M., Chou, C., Irish, V. E., Dickie, R., Elizondo, P., Wong, R., Brintnell, M., Elsasser, M., Lassar, W. M., Pierce, K. M., Leaitch, W. R., MacDonald, A. M., Platt, A., ToomSauntry, D., Sarda-Estève, R., Schiller, C. L., Suski, K. J., Hill, T. C. J., Abbatt, J. P. D., Huffman, J. A., DeMott, P. J., and Bertram, A. K.: Size-resolved measurements of ice-nucleating particles at six locations in North America and one in Europe, Atmos. Chem. Phys., 16, 1637-1651, https://doi.org/10.5194/acp16-1637-2016, 2016.

McCluskey, C. S., DeMott, P. J., Prenni, A. J., Levin, E. J., McMeeking, G. R., Sullivan, A. P., Hill, T. C., Nakao, S., Carrico, C. M., and Kreidenweis, S. M.: Characteristics of atmospheric ice nucleating particles associated with biomass burning in the 
US: Prescribed burns and wildfires, J. Geophys. Res.-Atmos., 119, 10458-10470, 2014.

McCluskey, C. S., Hill, T. C., Malfatti, F., Sultana, C. M., Lee, C., Santander, M. V., Beall, C. M., Moore, K. A., Cornwell, G. C., and Collins, D. B.: A dynamic link between ice nucleating particles released in nascent sea spray aerosol and oceanic biological activity during two mesocosm experiments, J. Atmos. Sci., 74.1, 151-166, 2016.

McFarquhar, G. M., Ghan, S., Verlinde, J., Korolev, A., Strapp, J. W., Schmid, B., Tomlinson, J., Wolde, M., Brooks, S. D., Collins, D., Cziczo, D., Dubey, M., Fan, J. D., Flynn, C., Gultepe, I., Hubbe, J., Gilles, M., Kok, G., Laskin, A., Lawson, P., Liu, P., Liu, X., Lubin, D., Mazzoleni, C., Macdonald, A., Moffet, R., Morrison, H., Ovtchinnikov, M., Ronfeld, D., Shupe, M., Turner, D., Xie, S., Zelenyuk, A., and Glen, A.: Indirect and Semi-Direct Aerosol Campaign (ISDAC): The impact of arctic aerosols on clouds, B. Am. Meteorol. Soc., 92, 183-201, 2011.

Mishchenko, M. I. and Sassen, K.: Depolarization of lidar returns by small ice crystals: An application to contrails, Geophys. Res. Lett., 25, 309-312, 1998.

Murray, B., O'sullivan, D., Atkinson, J., and Webb, M.: Ice nucleation by particles immersed in supercooled cloud droplets, Chem. Soc. Rev., 41, 6519-6554, 2012.

Nicolet, M., Stetzer, O., and Lohmann, U.: Depolarization ratios of single ice particles assuming finite circular cylinders, Appl. Optics, 46, 4465-4476, 2007.

Nicolet, M., Stetzer, O., Lüönd, F., Möhler, O., and Lohmann, U.: Single ice crystal measurements during nucleation experiments with the depolarization detector IODE, Atmos. Chem. Phys., 10, 313-325, https://doi.org/10.5194/acp-10-313-2010, 2010.

Niemand, M., Möhler, O., Vogel, B., Vogel, H., Hoose, C., Connolly, P., Klein, H., Bingemer, H., DeMott, P., and Skrotzki, J.: A particle-surface-area-based parameterization of immersion freezing on desert dust particles, J. Atmos. Sci., 69, 3077-3092, 2012.

Noel, V. and Sassen, K.: Study of planar ice crystal orientations in ice clouds from scanning polarization lidar observations, J. Appl. Meteorol., 44, 653-664, 2005.

Pinto, J. O.: Autumnal mixed-phase cloudy boundary layers in the Arctic, J. Atmos. Sci., 55, 2016-2038, 1998.

Pithan, F., Medeiros, B., and Mauritsen, T.: Mixed-phase clouds cause climate model biases in Arctic wintertime temperature inversions, Clim. Dynam., 43, 289-303, 2014.

Prenni, A., Tobo, Y., Garcia E., DeMott, P., Huffman J., McCluskey, C., Kreidenweis, S., Prenni, J., Pöhlker, C., and Pöschl, U.: The impact of rain on ice nuclei populations at a forested site in Colorado, Geophys. Res. Lett., 40, 227-231, 2013.

Pruppacher, H. R. and Klett, J. D.: Microphysics of Clouds and Precipitation, Second revised and expanded edition, Springer Science \& Business Media, New York City, New York, 2010.

Rogers, D. C.: Development of a continuous flow thermal gradient diffusion chamber for ice nucleation studies, Atmos. Res., 22, 149-181, 1988.

Rogers, D. C., DeMott, P. J., Kreidenweis, S. M., and Chen, Y.: A continuous-flow diffusion chamber for airborne measurements of ice nuclei, J. Atmos. Ocean Tech., 18, 725-741, 2001.

Schnaiter, M., Järvinen, E., Vochezer, P., Abdelmonem, A., Wagner, R., Jourdan, O., Mioche, G., Shcherbakov, V. N., Schmitt, C. G., Tricoli, U., Ulanowski, Z., and Heymsfield, A. J.: Cloud chamber experiments on the origin of ice crystal complex- ity in cirrus clouds, Atmos. Chem. Phys., 16, 5091-5110, https://doi.org/10.5194/acp-16-5091-2016, 2016.

Smith, H. R., Connolly, P. J., Webb, A. R., and Baran, A. J.: Exact and near backscattering measurements of the linear depolarisation ratio of various ice crystal habits generated in a laboratory cloud chamber, J. Quant. Spectrosc. Ra., 178, 361-378, 2016.

Tan, I., Storelvmo, T., and Zelinka, M. D.: Observational constraints on mixed-phase clouds imply higher climate sensitivity, Science, 352, 224-227, 2016.

Vali, G.: Nucleation terminology, B. Am. Meteorol. Soc., 66, 14261427, 1985.

Vali, G., DeMott, P. J., Möhler, O., and Whale, T. F.: Technical Note: A proposal for ice nucleation terminology, Atmos. Chem. Phys., 15, 10263-10270, https://doi.org/10.5194/acp-15-102632015, 2015.

Wagner, R., Höhler, K., Möhler, O., Saathoff, H., and Schnaiter, M.: Crystallization and immersion freezing ability of oxalic and succinic acid in multicomponent aqueous organic aerosol particles, Geophys. Res. Lett., 42, 2464-2472, 2015.

Warren, S. G. and Brandt, R. E.: Optical constants of ice from the ultraviolet to the microwave: A revised compilation, J. Geophys. Res., 113, D14220, https://doi.org/10.1029/2007JD009744, 2008.

Wendisch, M., Pilewskie, P., Pommier, J., Howard, S., Yang, P., Heymsfield, A. J., Schmitt, C. G., Baumgardner, D., and Mayer, B.: Impact of cirrus crystal shape on solar spectral irradiance: A case study for subtropical cirrus, J. Geophys. Res.-Atmos., 110, 2156-2202, 2005.

Wex, H., Augustin-Bauditz, S., Boose, Y., Budke, C., Curtius, J., Diehl, K., Dreyer, A., Frank, F., Hartmann, S., Hiranuma, N., Jantsch, E., Kanji, Z. A., Kiselev, A., Koop, T., Möhler, O., Niedermeier, D., Nillius, B., Rösch, M., Rose, D., Schmidt, C., Steinke, I., and Stratmann, F.: Intercomparing different devices for the investigation of ice nucleating particles using Snomax ${ }^{\circledR}$ as test substance, Atmos. Chem. Phys., 15, 14631485, https://doi.org/10.5194/acp-15-1463-2015, 2015.

Wylie, D. P. and Menzel, W. P.: Eight years of high cloud statistics using HIRS, J. Climate, 12, 170-184, 1999.

Xu, G., Sun, B., Brooks, S. D., Yang, P., Kattawar, G. W., and Zhang, X.: Modeling the inherent optical properties of aquatic particles using an irregular hexahedral ensemble, J. Quant. Spectrosc. Ra., 191, 30-39, 2017.

Yakobi-Hancock, J. D., Ladino, L. A., and Abbatt, J. P. D.: Feldspar minerals as efficient deposition ice nuclei, Atmos. Chem. Phys., 13, 11175-11185, https://doi.org/10.5194/acp-13-11175-2013, 2013.

Yang, P. and Liou, K.: Geometric-optics-integral-equation method for light scattering by nonspherical ice crystals, Appl. Optics, 35, 6568-6584, 1996.

Yang, P., Liou, K.-N., Bi, L., Liu, C., Yi, B., and Baum, B. A.: On the radiative properties of ice clouds: Light scattering, remote sensing, and radiation parameterization, Adv. Atmos. Sci., 32, 32-63, 2015.

Yoshida, R., Okamoto, H., Hagihara, Y., and Ishimoto, H.: Global analysis of cloud phase and ice crystal orientation from Cloud Aerosol Lidar and Infrared Pathfinder Satellite Observation (CALIPSO) data using attenuated backscattering and depolarization ratio, J. Geophys. Res.-Atmos., 115, D00H32, https://doi.org/10.1029/2009JD012334, 2010. 
Zimmerman, N., Presto, A. A., Kumar, S. P. N., Gu, J., Hauryliuk, A., Robinson, E. S., Robinson, A. L., and Subramanian, R.: Closing the gap on lower cost air quality monitoring: machine learning calibration models to improve low-cost sensor performance, Atmos. Meas. Tech. Discuss., https://doi.org/10.5194/amt-2017260, in review, 2017.
Zolles, T., Burkart, J., Häusler, T., Pummer, B., Hitzenberger, R., and Grothe, H.: Identification of ice nucleation active sites on feldspar dust particles, J. Phys. Chem. A, 119, 2692-2700, 2015. 